\title{
Chapter 4 \\ Biomass Productivity-Based Mapping of Global Land Degradation Hotspots
}

\author{
Quang Bao Le, Ephraim Nkonya and Alisher Mirzabaev
}

\begin{abstract}
Land degradation affects negatively the livelihoods and food security of global population. There have been recurring efforts by the international community to identify the global extent and severity of land degradation. Using the long-term trend of biomass productivity as a proxy of land degradation at global scale, we identify the degradation hotspots in the world across major land cover types. We correct factors confounding the relationship between the remotely sensed vegetation index and land-based biomass productivity, including the effects of inter-annual rainfall variation, atmospheric fertilization and intensive use of chemical fertilizers. Our findings show that land degradation hotpots cover about $29 \%$ of global land area and are happening in all agro-ecologies and land cover types. This figure does not include all areas of degraded lands, it refers to areas where land degradation is most acute and requires priority actions in both in-depth research and management measures to combat land degradation. About 3.2 billion people reside in these degrading areas. However, the number of people affected by land degradation is likely to be higher as more people depend on the continuous flow of ecosystem goods and services from these affected areas. Land improvement has occurred in about $2.7 \%$ of global land area during the last three decades, suggesting that with appropriate actions land degradation trend could be reversed. We also identify concrete aspects in which these results should be interpreted with cautions, the limitations of this work and the key areas for future research.
\end{abstract}

\footnotetext{
Q.B. Le (ه)

CGIAR Research Program on Dryland Systems (CRP-DS),

International Center for Agricultural Research in the Dry Areas (ICARDA),

PO Box 950764, Amman 11195, Jordan

e-mail: q.le@cgiar.org; q.le@alumni.ethz.ch

E. Nkonya

International Food Policy Research Institute (IFPRI), 2033 K Street NW, Washington, DC 20006, USA
}

\author{
A. Mirzabaev \\ Center for Development Research (ZEF), University of Bonn, Walter Flex Str 3, \\ 53113 Bonn, Germany \\ (C) The Author(s) 2016 \\ E. Nkonya et al. (eds.), Economics of Land Degradation \\ and Improvement - A Global Assessment for Sustainable Development, \\ DOI 10.1007/978-3-319-19168-3_4
}


Keywords Land degradation - Land improvement - NDVI • Rainfall variation • Fertilization

\section{Introduction}

Land degradation is a global problem affecting at least a quarter of the global land area (Lal et al. 2012) and seriously undermining the livelihoods, especially of the poor, in all agro-ecologies across the world (Nkonya et al. 2011). Although land degradation has been critical problem throughout the history (Diamond 2005), it has attained its current global scales, becoming a major global issue especially since the second half of the 20th century (Nkonya et al. 2011). Since the first global mapping of desertification in 1977 (Dregne 1977), there have been numerous efforts at global mapping of land degradation (Oldeman et al. 1990; USDA-NRCS 1998; Eswaran et al. 2001). The earlier generation of these studies had been constrained by lack of global level quantitative data which could be used for mapping soil and land degradation, and therefore were based on expert opinions. The developments in the remote sensing and satellite technologies allowed the later studies to be based on quantitative satellite data, such as Global Inventory Modelling and Mapping Studies (GIMMS) dataset of $64 \mathrm{~km}^{2}$-resolution of Normalized Difference Vegetation Index (NDVI) data, however, several methodological challenges still exist on more accurately estimating the land degradation hotspots (Vlek et al. 2010; Le et al. 2012).

In this context, addressing land degradation may require channeling substantial amounts of scarce resources and making long-term investments. These investments are likely to yield high levels of social returns and welfare improvements. However, all countries in the world have budgetary constraints, necessitating the prioritization of such investments. To combat land degradation, both on the international and national levels, policy makers often need information about areas of severe degradation in order to prioritize national budgets and plan strategic interventions (Vlek et al. 2010; Vogt et al. 2011; Le et al. 2012). To achieve this, accurate maps of land degradation hotspots - where land degradation is most acute, are needed. This study seeks to meet that objective at the global level.

As indicated above, there have been several efforts in the past to map land degradation at the global scale. The major objective of this global study is the identification of regions where degradation magnitude and extent are relatively high, i.e. geographic degradation hotspots, for prioritizing both preventive investments for the restoration or reclamation of degraded land, and subsequent focal ground-based studies. Consequently, this mapping of degradation hotspots is different from, indeed not as contentious as, the production of an accurate map of all degraded areas. 


\section{Literature Review}

Land degradation is a major global problem. There have been many efforts to map land degradation at global and regional scales (Dregne 1977; Oldeman et al. 1990; USDA-NRCS 1998; Eswaran et al. 2001; Herrmann et al. 2005; Wessels et al. 2007; Bai et al. 2008b, 2013; Hellden and Tottrup 2008; Hill et al. 2008; Vlek et al. 2008, 2010; Le et al. 2012; Conijn et al. 2013; Dubovyk et al. 2013). However, despite these efforts, the existing global maps of land degradation are weakened by serious shortcomings. The earlier mapping exercises used subjective expert opinion surveys as the basis for the maps, with unknown direction and magnitudes of measurement errors. The more recent of these studies are making use of now globally available remotely-sensed NDVI data (Tucker et al. 2005), but NDVI also has its own shortcomings as a proxy for land degradation, such as various confounding effects (Pettorelli et al. 2005). These include: (1) remnant cloud-cover effects in humid tropics, (2) soil moisture in sparse vegetative areas, which reduces the NDVI signal, (3) seasonal variations in vegetation phenology (proportional with weather seasonality) and time-series autocorrelation, (4) site-specific effects of vegetation structure and site conditions (e.g. topography and altitude). These confounding effects can be mitigated at some degree, but not completely removed. As a consequence, NDVI trend is always affected by unexpected noise, thus bearing considerable uncertainty in a way that where there are small magnitudes of NDVI trend, the risk that errors/noises in the NDVI data are larger than the trend itself is much higher (Tucker et al. 2005).

Moreover, there are major factors confounding the relationship between NDVI (NPP) trend and human-induced land degradation. These confounding effects include: (1) the effect of inter-annual rainfall variation on NDVI (NPP) (Herrmann et al. 2005), (2) the effect of atmospheric fertilization on vegetation greenness and growth (Boisvenue and Running 2006; Reay et al. 2008; Lewis et al. 2009; Buitenwerf et al. 2012; Le et al. 2012), and (3) intensive uses of chemical fertilizers in intensified croplands (Vlek et al. 1997; Potter et al. 2010; MacDonald et al. 2011). The biomass productivity of the land is often a low priority service in many urbanized areas, where space provision is usually the most expected service of the land.

To isolate human-induced biomass production decline from the one driven by rainfall, currently, there are different methods: residual trend analysis method (ResTrend) (Evans and Geerken 2004; Herrmann et al. 2005) (Wessels et al. 2007), the trend-correlation stepwise method (Trend-Correlation) (Le et al. 2012; Vlek et al. 2010; Vu et al. 2014a), or trend-correlation with the additional use of rain-use efficiency (RUE) (Bai et al. 2008a; Fensholt et al. 2013). The first two methods use the correlation between inter-annual NDVI and rainfall data for isolating pixels with biomass production decline not caused by rainfall inter-annual variation. If there is no other natural drivers of biomass production decline besides the reduction of annual rainfall, the biomass production decline in these pixels is likely caused by human activities. The comparisons between the uses of two methods at global level (Dent et al. 2009) and national level (Vu et al. 2014a) showed similar results. While rain-use efficiency has been recently used in some land degradation assessments in 
dry lands (Wessels et al. 2007; Fensholt et al. 2013), there are concerns about the use of rain-use efficiency for continental and global scale (Dent et al. 2009), especially in the humid tropics where rainfall is generally not a limited factor of primary productivity.

The effect of atmospheric fertilization caused by elevated levels of $\mathrm{CO}_{2}$ and $\mathrm{NO}_{\mathrm{x}}$ in the atmosphere (Dentener 2006; Reay et al. 2008) complicates the global assessment of land degradation using the NDVI-based approach. Increased atmospheric fertilization (AF) can cause a divergence between greenness trend and soil fertility change as the fertilization effect has not been substantially mediated through the soil. The rising level of atmospheric $\mathrm{CO}_{2}$ stimulates photosynthesis in plants' leaves, thus increasing NPP, but the soil fertility may not necessarily be proportional with the above ground biomass improvement. The wet deposition of reactive nitrogen and other nutrients may affect positively plant growths as foliate fertilization without significantly contributing to the soil nutrient pool, or compensating nutrient losses by soil leaching and erosion. Global observations, both field measurements (Boisvenue and Running 2006; Lewis et al. 2009; Buitenwerf et al. 2012) and remotely sensed data analyses (Vlek et al. 2010; Fensholt et al. 2012; Le et al. 2012) show long-term improvement of biomass productivity in large areas that cannot be attributed to either human interventions or rainfall improvement. In Africa, the biomass increased at a rate of $0.63 \pm 0.31 \mathrm{mg} \mathrm{ha}^{-1}$ year $^{-1}$ over the past 4 decades for closed-canopy tropical forest sites with ample rain and free of human interventions (Lewis et al. 2009).

As NDVI values can be affected by several site- and land cover-specific factors (Pinter et al. 1985; Markon et al. 1995; Thomas 1997; Mbow et al. 2013), different locations with the same NDVI value are not necessarily have the same biomass productivity. Thus, comparison of biomass productivity between pixels using NDVI is a pitfall that should be avoided (Pettorelli et al. 2005). Recent studies suggested interpreting the NDVI trend results for each spatial stratum of social-ecological conditions in order to gain more insights about likely degradation processes and affecting factors in the delineated hotspots (Vlek et al. 2010; Sommer et al. 2011; Le et al. 2012; Vu et al. 2014b). Because land use/cover refers to ecosystem exploitation (Nachtergaele and Petri 2008) and is conditioned by several anthropogenic factors that define the social and ecological contexts for interpreting causalities from statistical results, broad land-use classes have been recommended for stratifying causal analyses and interpretations of land degradation (Vlek et al. 2010; Sommer et al. 2011; Vu et al. 2014b).

\section{The Conceptual Framework}

In this study, "land degradation" is understood in a broad sense. From internationally authoritative concepts of United Nations Convention to Combat Desertification (UNCCD 2004) and Millennium Ecosystem Assessment (MEA 2005), land degradation is defined as the persistent reduction or loss of land 
ecosystem services, notably the primary production service (Safriel 2007; Vogt et al. 2011). The aspects emphasized in this definition of land degradation include:

1. "Land" is understood as a terrestrial ecosystem that includes not only soil resources, but also vegetation, water, other biota, landscape setting, climate attributes, and ecological processes (MEA 2005) that operate within the system, ensuring its functions and services.

2. The definition focuses on the ecological services of the land: land degradation makes sense to our society only in the context of human benefits derived from land ecosystems uses (Safriel 2007). Negative changes in soil component (e.g. soil erosion, deteriorations of physical, chemical, and biological soil properties) are concerned as much as how serious these changes result in reductions of supporting (e.g. primary production), provisioning (e.g. biological products including foods) and regulating (e.g. carbon sequestration) services of the land (i.e. land ecosystem).

As a consequence, the definition emphasizes the pivotal role of primary production among a wide range of land's services. The crucial reason for this emphasis is that primary production generates products of biological origin, on which much of other ecosystem services depend (Safriel 2007). The primary production is the basis of food production, regulates water, energy, and nutrient flows in land ecosystems, sequestrates carbon dioxide from the atmosphere and generally provides habitats for diverse species (MEA 2005).

\section{Methodology and Data}

The methodological approaches applied in this study build on this previous literature and, in fact, seek to address some of the shortcomings of the previous research on global land degradation hotspots mapping.

\section{Proxy Indicator Approach to Mapping of Degradation Hotspots}

In the context of land degradation hotspots mapping, land degradation proxies (i.e. key indicators that approximate relevant processes of land degradation) are often used to delineate degradation hotspots. Although using proxies of land degradation is always prone to considerable uncertainties, the proxy method is relevant for mapping global, continental and national degradation hotspots due to the following reasons:

1. The main target is the areas with high magnitude and extent of degradation, i.e. where temporal and spatial variations of the used proxies are high and observable. This helps mitigate the adverse effects of the inherently high 
uncertainty of the used proxies ( Vu et al. 2014a). The lower is the temporal and spatial variation of the used proxies, the lower is the relevance of the proxy method.

2. The considered scale is global, or continental or national and the related need is to delineate degradation hotspot at coarse resolution (e.g. 1-10 km) (Vogt et al. 2011).

3. There are no other data alternatives for long-term ( $>2$ decades), large scale (global or continental) assessments (Vlek et al. 2010; Fensholt et al. 2012).

4. Efforts to improve global/continental land degradation assessment require the first version of a global land degradation map to guide where and what needed to be verified in the next steps.

\section{Long-Term Trend of Annual NDVI as the Proxy of Long-Term Biomass Productivity Decline}

Given the global scale and long-term perspectives of the study, we used the long-term trend of inter-annual mean Normalized Difference Vegetation Index (NDVI) over the period 1982-2006 as a proxy for a persistent decline or improvement in the Net Primary Productivity (NPP) of the land, thereby delineating past land degradation hotspots. This NDVI-based assessment of land degradation has been used by many studies (Bai et al. 2008b; Hellden and Tottrup 2008; Vlek et al. 2010; Le et al. 2012). However, as we highlighted in the literature review, NDVI as a proxy for land degradation has several caveats. Our strategy to address these caveats in this NDVI-based mapping of land degradation hotspots is summarized in Table 4.1.

\section{GIMMSg-NDVI Data}

The employed dataset of vegetation index Global Inventory Modeling and Mapping Studies (GIMMS) Satellite Drift Corrected and NOAA-16 incorporated Normalized Difference Vegetation Index (NDVI), Monthly 1981-2006, is called GIMMSgNDVI dataset. This dataset is available for free at the Global Land Cover Facility (GLCF), the University of Maryland (GLCF-http://glcf.umiacs.umd.edu/data/ gimms/-accessed in 01 May 2013).

This GIMMSg-NDVI version is selected for analysis because of several reasons. For global land degradation assessment over long terms, there may be no other alternative data. At present the GIMMS-NDVI data archive is the only global coverage dataset spanning 1982 to recent time. The NDVI dataset was calibrated and corrected for view geometry, volcanic aerosols, and other effects not related to vegetation change (Pinzon et al. 2005; Tucker et al. 2005). As a result, this new 
Table 4.1 Measures for mitigating or correcting confounding effects in the presented NDVI-based mapping of land degradation hotspots

\begin{tabular}{|c|c|c|c|}
\hline $\begin{array}{l}\text { Confounding } \\
\text { factors }\end{array}$ & $\begin{array}{l}\text { Affected } \\
\text { relationship or } \\
\text { process }\end{array}$ & $\begin{array}{l}\text { Mitigating/correcting } \\
\text { measure used in this } \\
\text { study }\end{array}$ & $\begin{array}{l}\text { Done/advised by } \\
\text { other studies }\end{array}$ \\
\hline $\begin{array}{l}\text { Remnant } \\
\text { cloud-cover effect } \\
\text { in humid tropics }\end{array}$ & $\begin{array}{l}\text { NDVI versus } \\
\text { NPP weakened }\end{array}$ & $\begin{array}{l}\text { Only non-flagged pixels } \\
\text { used }(2)^{\mathrm{a}}\end{array}$ & $\begin{array}{l}\text { Tucker et al. (2005), } \\
\text { Brown et al. (2006) }\end{array}$ \\
\hline $\begin{array}{l}\text { Effect of soil } \\
\text { moisture in sparse } \\
\text { vegetative areas }\end{array}$ & $\begin{array}{l}\text { NDVI versus } \\
\text { NPP weakened }\end{array}$ & $\begin{array}{l}\text { Eliminating pixel with } \\
\text { NDVI }<0.05 \text {, arid zone, } \\
\text { cautions in sparse } \\
\text { vegetation areas }(2)^{\mathrm{a}}\end{array}$ & $\begin{array}{l}\text { de Jong et al. (2012), } \\
\text { Fensholt et al. (2012), } \\
\text { Le et al. (2012) }\end{array}$ \\
\hline $\begin{array}{l}\text { Seasonal variations } \\
\text { in vegetation } \\
\text { phenology and } \\
\text { time-series } \\
\text { autocorrelation }\end{array}$ & $\begin{array}{l}\text { Inter-annual } \\
\text { NDVI } \\
\text { (NPP) trend } \\
\text { confounded }\end{array}$ & $\begin{array}{l}\text { Use annually average } \\
\text { NDVIs instead of } \\
\text { bi-weekly or monthly } \\
\text { NDVIs }(1)^{\mathrm{a}}\end{array}$ & $\begin{array}{l}\text { Bai et al. (2008b), } \\
\text { Hellden and Tottrup } \\
\text { (2008), de Jong et al. } \\
(2011,2012)\end{array}$ \\
\hline $\begin{array}{l}\text { Site-specific effects } \\
\text { of vegetation/crop } \\
\text { structure and site } \\
\text { conditions }\end{array}$ & $\begin{array}{l}\text { NDVI versus } \\
\text { NPP weakened }\end{array}$ & $\begin{array}{l}\text { No spatial trend of } \\
\text { NDVI used }(3)^{\mathrm{a}} \\
\text { Land-use/cover-specific } \\
\text { interpretation }(6)^{\mathrm{a}} \\
\text { Eliminate/cautious with } \\
\text { area having LAI > } 4(6)^{\mathrm{a}}\end{array}$ & $\begin{array}{l}\text { Pettorelli et al. } \\
\text { (2005), Vu et al. } \\
\text { (2014a), Carlson and } \\
\text { Ripley (1997), Vu } \\
\text { et al. (2014a) }\end{array}$ \\
\hline $\begin{array}{l}\text { Larger } \\
\text { errors/noises in the } \\
\text { NDVI data } \\
\text { compared to the } \\
\text { small NDVI trend } \\
\text { itself }\end{array}$ & $\begin{array}{l}\text { Not reliable } \\
\text { Inter-annual } \\
\text { NDVI } \\
\text { (NPP) trend }\end{array}$ & $\begin{array}{l}\text { Not consider pixels with } \\
\text { no statistical } \\
\text { significance or very } \\
\text { small magnitude of } \\
\text { NDVI trend (e.g. } \\
<10 \% / 25 \text { years) }(3)^{\mathrm{a}}\end{array}$ & $\begin{array}{l}\text { Le et al. (2012), Vu } \\
\text { et al. (2014a) }\end{array}$ \\
\hline $\begin{array}{l}\text { Effect of } \\
\text { inter-annual rainfall } \\
\text { variation on NDVI } \\
\text { (NPP) }\end{array}$ & $\begin{array}{l}\text { Mixture } \\
\text { between } \\
\text { climate-driven } \\
\text { and } \\
\text { human-induced } \\
\text { NPP trend }\end{array}$ & $\begin{array}{l}\text { Correct partly rainfall } \\
\text { effect by consider } \\
\text { NDVI-rainfall } \\
\text { correlation }(4)^{\mathrm{a}}\end{array}$ & $\begin{array}{l}\text { Herrmann et al. } \\
\text { (2005), Bai et al. } \\
(2008 b) \text {, Le et al. } \\
(2012)\end{array}$ \\
\hline $\begin{array}{l}\text { Effect of } \\
\text { atmospheric } \\
\text { fertilization } \\
\text { (AF) on NDVI } \\
\text { (NPP) }\end{array}$ & $\begin{array}{l}\text { Mixture } \\
\text { between } \\
\text { climate-driven } \\
\text { and } \\
\text { human-induced } \\
\text { NPP trend }\end{array}$ & $\begin{array}{l}\text { Correct partly AF effect } \\
\text { by consider NPP growth } \\
\text { in pristine areas (5) }\end{array}$ & Le et al. (2012) \\
\hline $\begin{array}{l}\text { Effect of intensive } \\
\text { fertilizer uses on } \\
\text { NDVI (NPP) }\end{array}$ & $\begin{array}{l}\text { Mixture } \\
\text { between } \\
\text { fertilizer-driven } \\
\text { NPP soil-based } \\
\text { NPP }\end{array}$ & $\begin{array}{l}\text { Masking areas with high } \\
\text { fertilizer use for } \\
\text { follow-up study ( } 7 \text { ) }\end{array}$ & \\
\hline $\begin{array}{l}\text { Irrelevance of } \\
\text { considering NPP in } \\
\text { urbanized areas }\end{array}$ & $\begin{array}{l}\text { NPP is not } \\
\text { relevant } \\
\text { indicator }\end{array}$ & $\begin{array}{l}\text { Masking urban areas } \\
\text { from the consideration } \\
\text { (2) }\end{array}$ & $\begin{array}{l}\text { Le et al. (2012), Vu } \\
\text { et al. (2014a) }\end{array}$ \\
\hline
\end{tabular}

${ }^{a}$ Number within parentheses indicates the related step in Fig. 4.1 


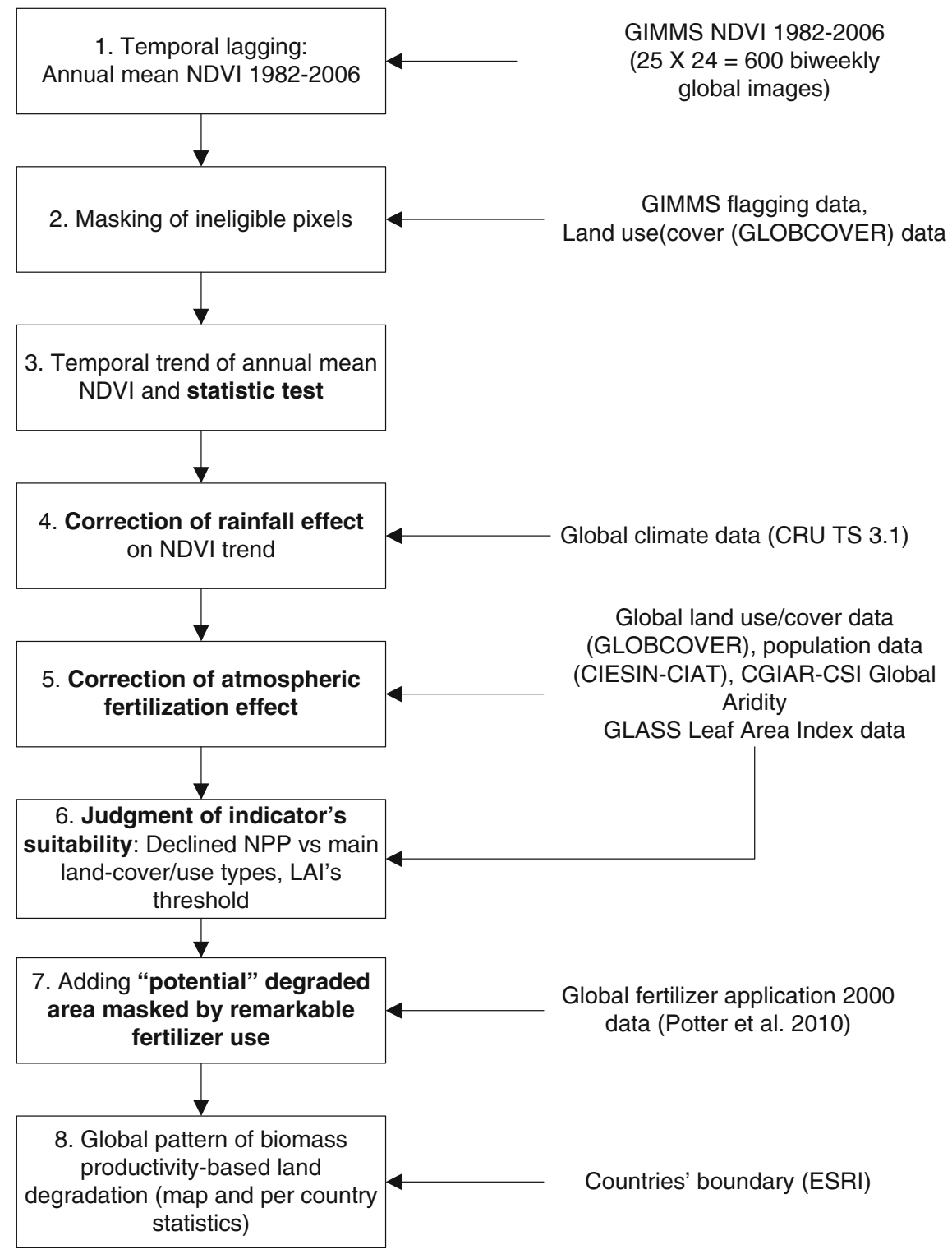

Fig. 4.1 Procedure of biomass productivity-based assessment of NDVI. Note The bold text indicates relatively new features compared to previous studies

GIMMS NDVI dataset, used in this study, is relatively consistent over time and is of higher quality compared to the previous versions produced by the GIMMS group (Brown et al. 2006). Using Terra MODIS NDVI as a reference (Fensholt et al. 2009) in Sahel region found that the GIMMS NDVI data set is well-suited for long 
term vegetation studies of the Sahel-Sudanian areas. The GIMMSg-NDVI archive "should provide a large improvement over previously used NDVI data sets, because the data are collected by one series of instruments, and they give a more realistic representation of the spatial and temporal variability of vegetation patterns over the globe" (GLCF accessed in 01 May 2013).

Validity of the GIMMS dataset has been discussed in previous studies (Tucker et al. 2005; Brown et al. 2006), and is subjected to ongoing validation (Fensholt et al. 2012; GLCF accessed in 01 May 2013). The procedure of the analytical flow is shown in Fig. 4.1. The detailed explanations of major analysis steps are given in the corresponding results sections for better contextual understanding.

\section{Results}

\section{Aggregating Annual Mean NDVI Time-Series (1982-2006) (Step 1 in Fig. 4.1)}

To minimize the confounding effects of seasonal variations and time-series autocorrelation, we used annual average NDVI instead of the original bi-weekly GIMMS NDVI time-series, which is similar to Hellden and Tottrup (2008) and Vlek et al. (2010). This treatment is supported by the recent findings of de Jong et al. (2011). They found that inconsistencies between the linear trends of annually aggregated GIMMS NDVI and the seasonality-corrected, non-parametric trends of the original GIMMS NDVI time-series (biweekly) were mainly on areas with weak or non-significant NDVI trends, which are not central in our hotspot approach. The year 1981 was excluded because it has only data for the later 6 months (JulyDecember). As a result, there are 25 annual mean NDVI images calculated from 600 original GIMMSg images.

\section{Masking Ineligible Pixels (Step 2 in Fig. 4.1)}

As explained in Table 4.1, pixels with the following statuses were masked from the course of the analyses. To partly avoid the effect of cloud cover or cloud shade, flagged GIMMS pixels, i.e. flag $>0$ indicates a not good value of NDVI, were masked. As NDVI is not a suitable indicator of NPP in bare, or very sparse vegetation, pixels with NDVI $<0.05$ were masked. Pixels with bare surface, urban and industrial areas, based on GLOBCOVER version 2.2 data (Bicheron et al. 2008), were masked. Figure 4.2 depicts the resulting global pattern of the average annual mean NDVI over 1982-2006 on the eligible (non-grey) areas. 


\section{Significant Trend of Annual Mean NDVI Over 1982-2006 (25 Years) (Step 4 in Fig. 4.1)}

\section{Temporal Slope Metrics and Statistical Test}

For each pixel $i$, the long-term trend of annual NPP (via vegetation index) can be formalized by the slope coefficient (Ai) in the simple linear regression relationship

$$
V_{\mathrm{i}}=A_{\mathrm{i}} \times t+B_{\mathrm{i}}
$$

where $V_{\mathrm{i}}=$ annual mean NDVI, $A_{\mathrm{i}}=$ long-term trend of NDVI, $t=$ year (elapsing from 1982 to 2006), $B_{\mathrm{i}}=$ intercept (an indicator for a possible delay in the onset of degradation). The computed slope coefficient $A_{i}$ for each pixel was tested for statistical significance at different confidence levels at $90 \%(p<0.1)$, which is sufficient for long-term trend analyses of noisy parameters like NDVI (Le et al. 2012; Vlek et al. 2010).

Figure 4.3 shows the significant trend in a statistical manner only. A statistically significant trend can be with a too small magnitude that can be either not significant in practice, or lower than errors/noises in NDVI time-series. Both cases should not be meaningful for consideration. Thus, it is much more meaningful to look at the relative change in inter-annual NDVI compared to the period mean (see Fig. 4.2).

\section{Significant Biomass Productivity Decline}

Significant biomass productivity (annual mean NDVI) decline is defined by the following criteria: negative NDVI slope with a statistical significance $(p<0.1)$, and Meaningful magnitude of the NDVI decline: relative NDVI annual reduction $\geq$ $10 \% / 25$ years (or $\geq 0.4 \%$ /year) (Vlek et al. 2010; Le et al. 2012; Vu et al. 2014a). There are two reasons for selecting this cut-off threshold.

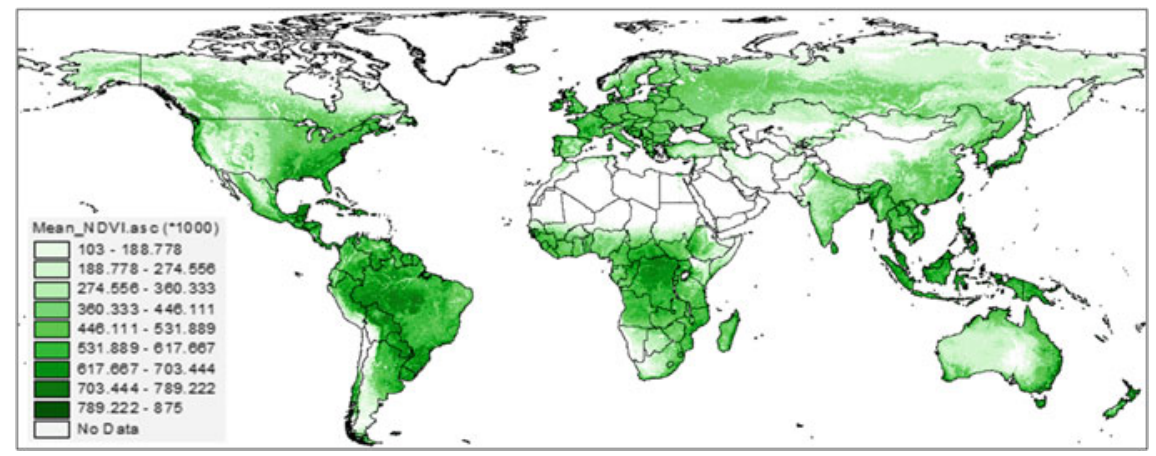

Fig. 4.2 Average annual mean NDVI (scale factor $=1000$ ) of the period 1982-2006 


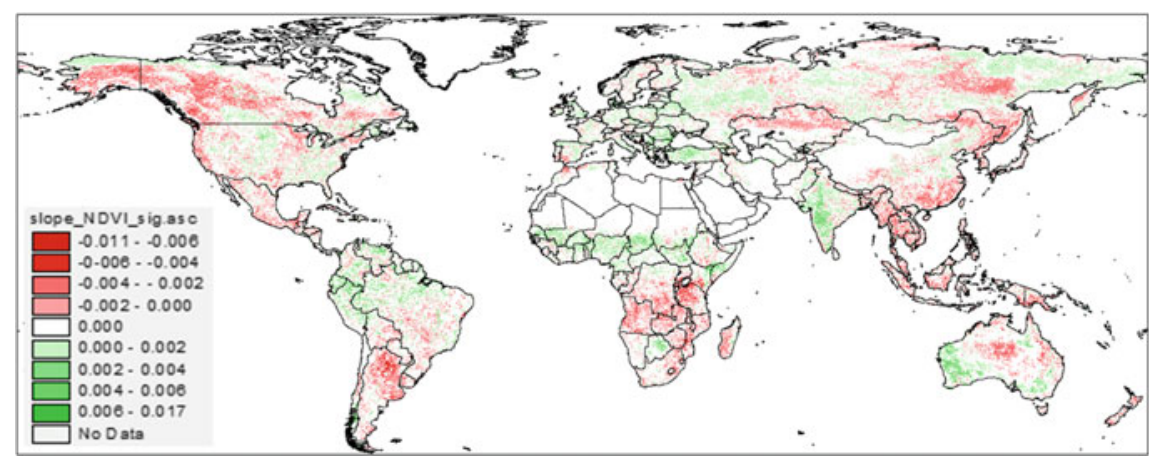

Fig. 4.3 Significant $(p<0.1)$ slope of inter-annual NDVI over 1982-2006. Notes White areas are with either no data, or statistically non-significant trend. There has been no minimal threshold of NDVI slope applied yet

First, from a common sense, a reduction rate of less than $0.4-0.5 \%$ per year can be considered to be insignificant in practice. Second, with these very small magnitudes of NDVI trend, the risk that inherent errors/noises in the NDVI data are larger than the trend itself is high, making the NDVI trend less reliable (Tucker et al. 2005). This cut-off value helps avoid that risk.

Figure 4.4 shows spatial pattern of annual decline of biomass productivity in percentages of the period mean of NDV (Fig. 4.4a) and in the dummy scale (i.e. $1=$ significant productivity decline, $0=$ otherwise) (Fig. 4.4b).

\section{Correction of Rainfall Variation Effect}

The significant decline of inter-annual NDVI shown in Fig. 4.4 can be attributed to either temporal variation in rainfall or human activities (e.g. land cover/use conversion and/or change in land use intensity). The annual rainfall data for the period 1982-2006, which was extracted from the TS 3.1 dataset of the Climatic Research Unit (CRU) at the University of East Anglia (UK), were used for the isolating purpose. The original data include grids of monthly rainfall data at a spatial resolution of $0.5^{\circ}$, covering the 1901-2006 period (Jones and Harris 2008). To match the spatial resolution of AVHRR-NDVI data for later analysis, the grid cells of rainfall data were re-sampled to match with the $8-\mathrm{km}$ resolution of NDVI data, using nearest neighbor statistics. The Trend-Correlation method is used to account for rainfall variation effect. The procedure of Trend-Correlation method (Vlek et al. 2010) involves: For each pixel, Pearson's correlation coefficient between inter-annual NDVI and rainfall over the 1982-2006 period $\left(R_{i}\right)$ is calculated. The statistical significance for pixel-based correlation coefficients at a confidence level of $95 \%(p<0.05)$ is tested. A pixel was considered to have a strong correlation between its inter-annual NDVI and rainfall if the correlation coefficient was 
(a)

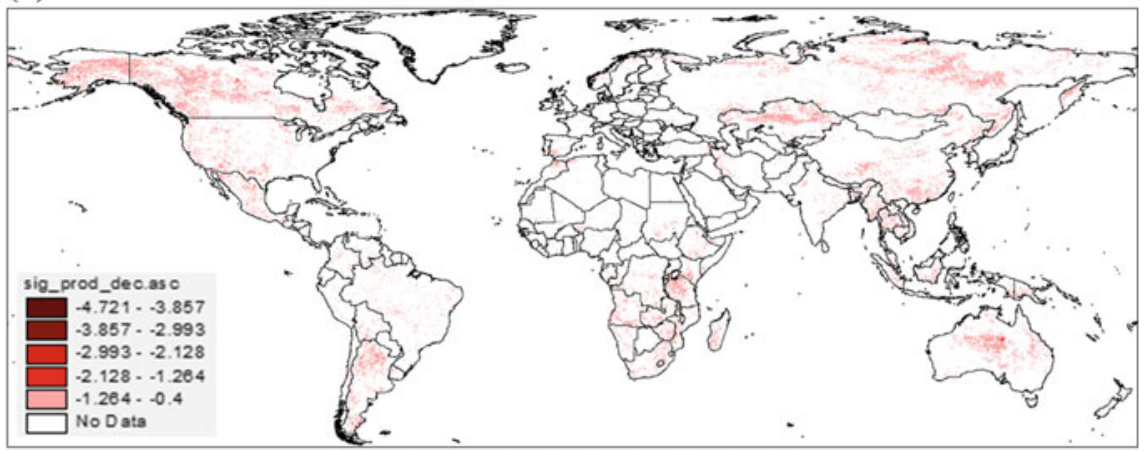

(b)

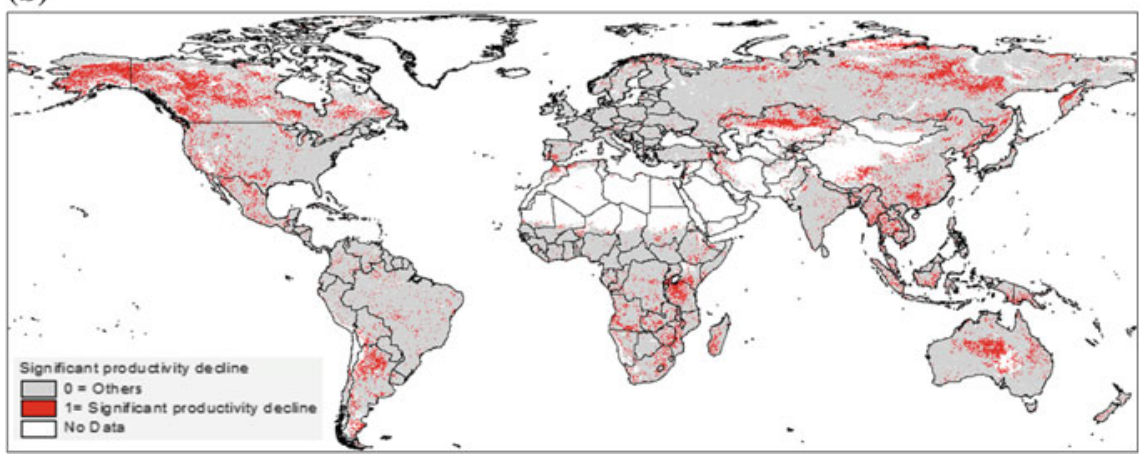

Fig. 4.4 Significant ( $p<0.1$ and reduction rate $\geq 10 \% / 25$ years) biomass productivity decline over 1982-2006. a Annual reduction rate (\% of period mean), b dummy scale (area of significant productivity decline $=15,336,128 \mathrm{~km}^{2}$ )

significant $(p<0.05)$ and greater than 0.5 or lower than -0.5 . If the pixel has a significantly negative NDVI trend (negative $A_{i}, p<0.1$ ) and a strongly positive vegetation-climate correlation $\left(R_{i}>0.5, p<0.05\right)$, the NDVI decline at the location was determined by the rainfall factor. Otherwise, the NDVI decline was likely caused by non-climate factors. The limitation of the method is that in the pixels with significantly negative NDVI trend and positive vegetation-rainfall correlation (or non-significant residue trend in ResTrend method), both rainfall and human effects can be mutually exclusive. The elimination of these pixels may also exclude some human-induced degradation areas. The long-term response of inter-annual NDVI to rainfall variation is shown in Fig. 4.5. Then, the NDVI decline pattern from which rainfall-driven pixels were masked is given in Fig. 4.6. 
(a)

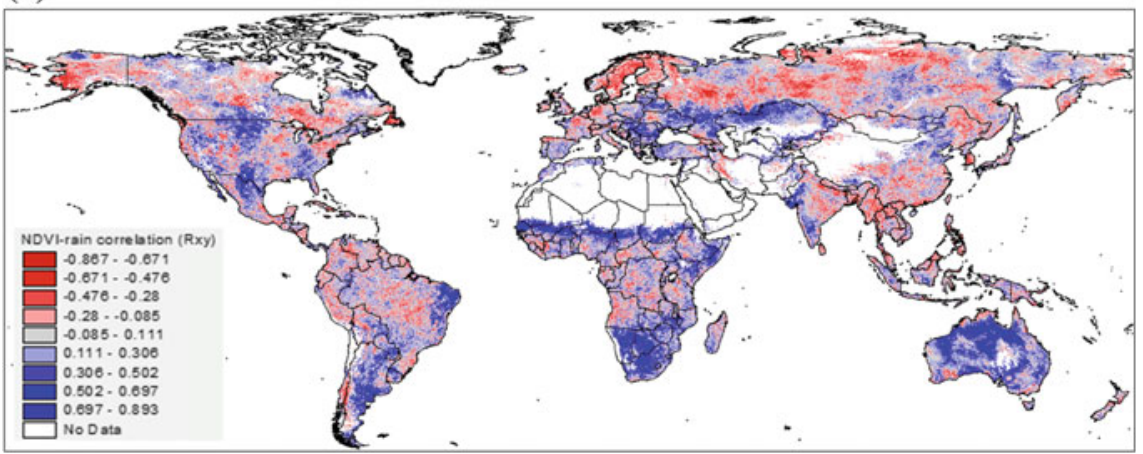

(b)

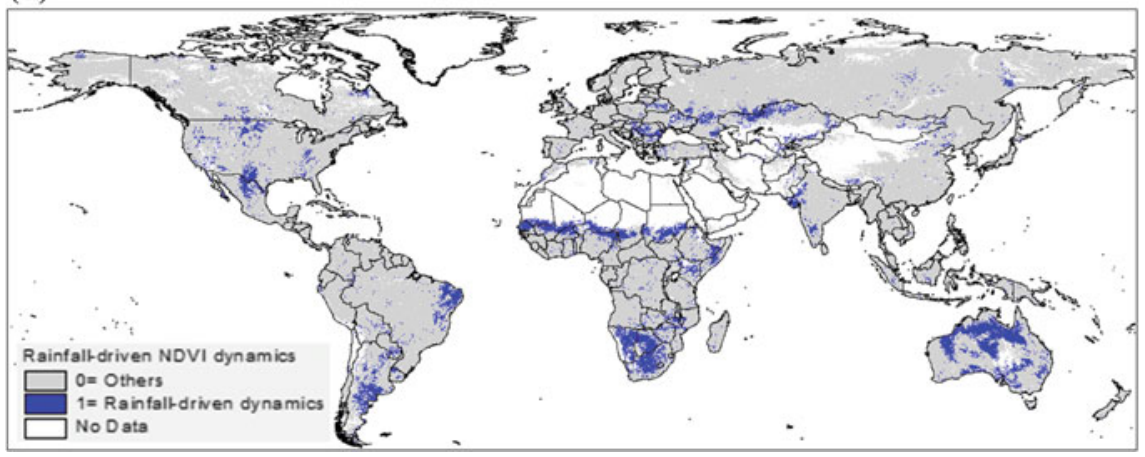

Fig. 4.5 Long-term response of inter-annual NDVI to rainfall variation (1982-2006): a correlation coefficient $\left(R_{x y}\right)$ between inter-annual NDVI and rainfall, $\mathbf{b}$ area of rainfall-driven NDVI dynamics $\left(p<0.05\right.$ and $R_{x y} \geq 0.5$ ) that was masked from further analysis (masked area in blue $=10,654,464 \mathrm{~km}^{2}$ )

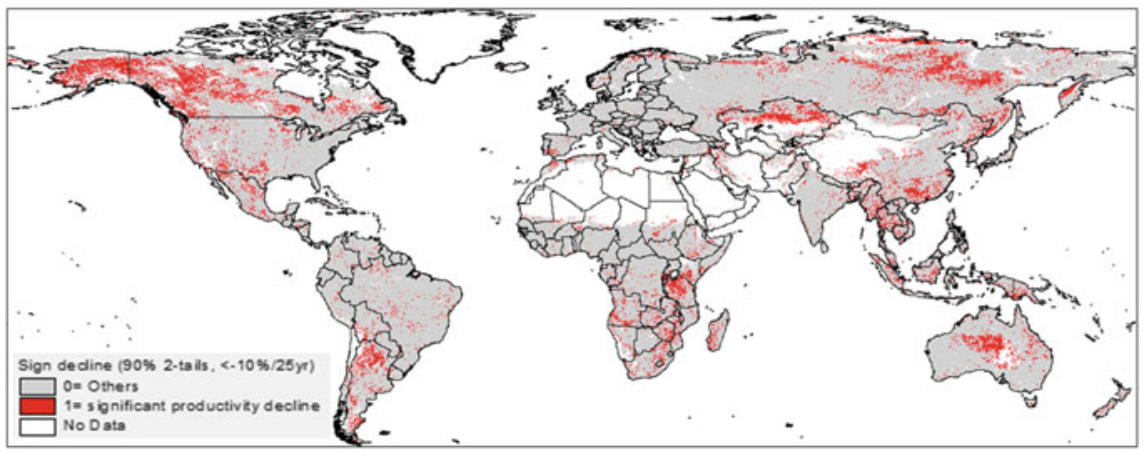

Fig. 4.6 Significant $(p<0.1$ and reduction rate $\geq 10 \% / 25$ years) biomass production (NDVI) decline corrected for rainfall effect (area in red $=14,525,952 \mathrm{~km}^{2}$ ) 


\section{Correction of Atmospheric Fertilization Effect (Step 5 in Fig. 4.1)}

\section{Calculate the Sub-component of AF-Driven Growth}

The actual change in vegetation productivity can be considered the net balance between the partial changes caused by human activities and those caused by natural processes (i.e. effects of rainfall and/or AF). In pristine vegetative areas, actual vegetation dynamics can be driven by only natural drivers as the human-induced component of biomass dynamics can be assumed to be zero. If these areas, in addition, have no correlation between biomass productivity and weather parameters, weather effects can be neglected and the actual growth can be assumed to be caused by atmospheric fertilization (Vlek et al. 2010). Thus, the quantum of AF-driven growth of a particular vegetation type can be found in the pristine (no significant human disturbance) areas of that type with no NDVI-rainfall correlation.

Based on the map in Fig. 4.6, the total land with significant biomass production decline $(p<0.1$, reduction rate $\geq 10 \% / 25$ years) corrected for rainfall effect is about 14.5 million $\mathrm{km}^{2}$, or about $10 \%$ of the total global land area (i.e. 226,968 pixels, or $14,525,952 \mathrm{~km}^{2}$ ). We defined the above-mentioned areas by applying an overlaying scheme as shown in Fig. 4.7.

As a result, we identified 246,159 pixels (i.e. $15,754,176 \mathrm{~km}^{2}$ ) belonging to 85 'pristine' (no significant human disturbance) Cover-Climate types that are all with no significant NDVI-rainfall correlation (see Fig. 4.8). As explained, vegetation biomass dynamics in these areas are likely driven by atmospheric fertilization (AF) effect.

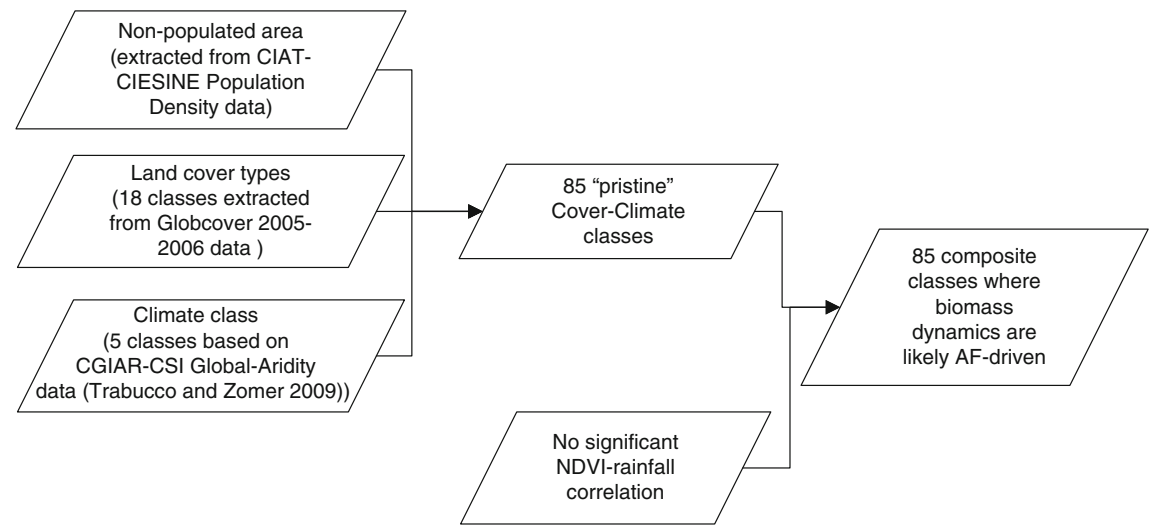

Fig. 4.7 Overlaying scheme for defining areas of pristine (no significant human disturbance) vegetation with no NDVI-rainfall correlation, where biomass dynamics are likely AF-driven 


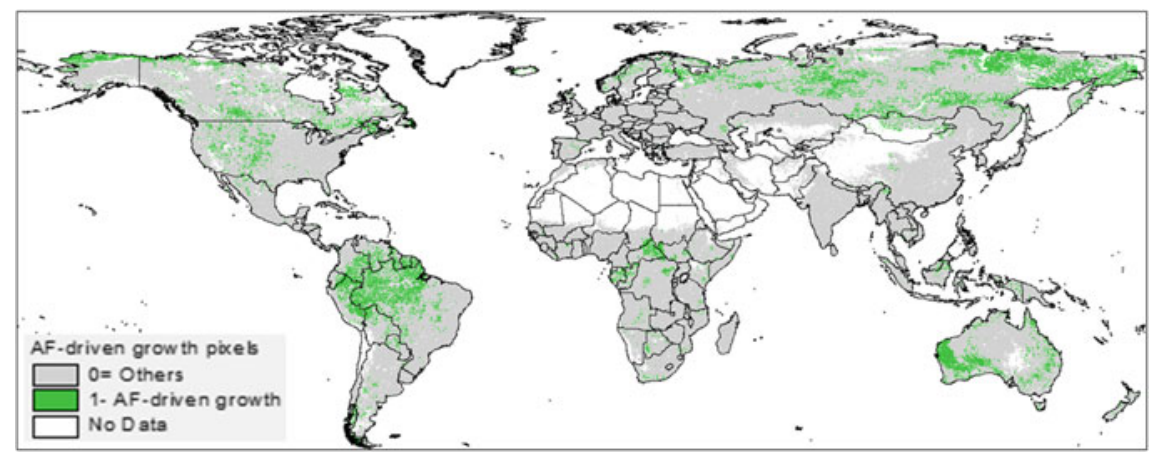

Fig. 4.8 Spatial pattern of pristine vegetation with no NDVI-rainfall correlation where biomass dynamics are likely AF-driven (area in green $=15,754,176 \mathrm{~km}^{2}$ )

The correction of AF effect was then done by three steps:

1. Calculate means of NDVI slope for each Cover-Climate-No Correlation types: $\mathrm{dNDVI}_{\mathrm{AF}, \mathrm{k}} / \mathrm{dt}$ where $\mathrm{k}$ indexes the Cover-Climate type.

2. Re-calculation of AF-adjusted inter-annual NDVI time-series through subtracting the NDVI data by quantum $\mathrm{dNDVI}_{\mathrm{AF}, \mathrm{k}} / \mathrm{dt}$. This re-calculation of NDVI time-series was specific for each Cover-Climate class k, i.e. AF-driven NDVI accrual for each class was used for recalculation of NDVI time-series on elsewhere with the same class

$$
\begin{aligned}
& \mathrm{NDVI}_{\mathrm{AF}-\text { adjusted,1983,k }}=\mathrm{NDVI}_{1982, \mathrm{k}}-1^{*} \mathrm{dNDVI}_{\mathrm{AF}, \mathrm{k}} / \mathrm{dt} \\
& \mathrm{NDVI}_{\mathrm{AF}-\text { adjusted,1984,k}}=\mathrm{NDVI}_{1982, \mathrm{k}}-2^{*} \mathrm{dNDVI}_{\mathrm{AF}, \mathrm{k}} / \mathrm{dt} \\
& \mathrm{NDVI}_{\mathrm{AF}-\text { adjusted,1985,k}}=\mathrm{NDVI}_{1982, \mathrm{k}}-3^{*} \mathrm{dNDVI}_{\mathrm{AF}, \mathrm{k}} / \mathrm{dt} \\
& \ldots \\
& \mathrm{NDVI}_{\mathrm{AF}-\text { adjusted,2006,k }}=\mathrm{NDVI}_{1982, \mathrm{k}}-24^{*} \mathrm{dNDVI}_{\mathrm{AF}, \mathrm{k}} / \mathrm{dt}
\end{aligned}
$$

3. Re-calculate the trend of inter-annual AF-adjusted NDVIs, test the statistical significance of the trend, and calculate $\mathrm{NDVI}_{\mathrm{AF}-\text { adjusted }}$-Rainfall correlation.

The AF-corrected significant biomass productivity decline is showed in Fig. 4.9a (in $\%$ of period-mean $\mathrm{NDVI}_{\mathrm{AF}-\text { adjusted }}$ ) and Fig. $4.9 \mathrm{~b}$ (in dummy scale). There are 633,443 pixels, i.e. $40,540,352 \mathrm{~km}^{2}$ of global land (i.e. $27 \%$ ) likely to have experienced significant biomass productivity decline given that the effects of rainfall and atmospheric fertilization are taken into account.

\section{Identification of Areas with Saturated NDVI and Relation to Land-Use/Cover Strata (Step 6 in Fig. 4.1)}

The NDVI-vegetation productivity relationship can be saturated, thus biased in areas with dense vegetation canopies (Pettorelli et al. 2005). In the areas having 
(a)

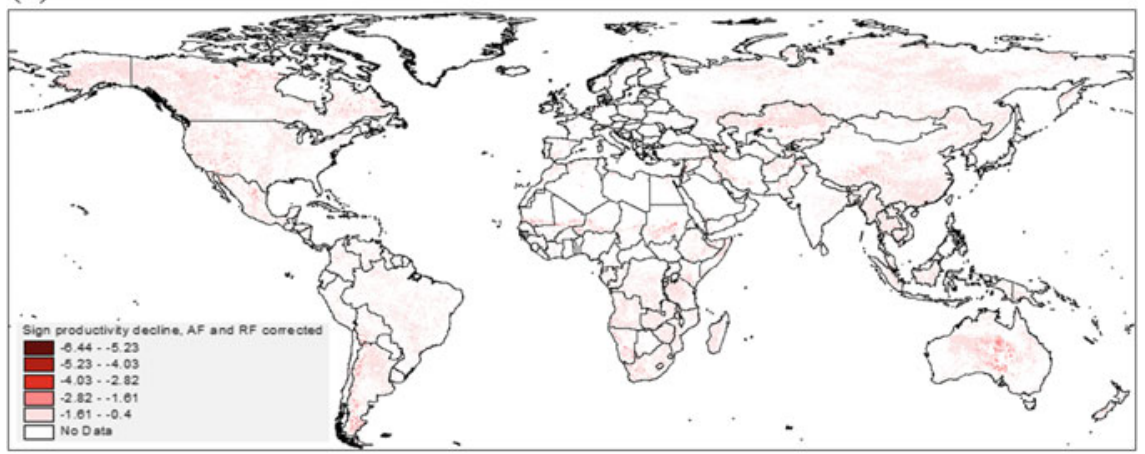

(b)

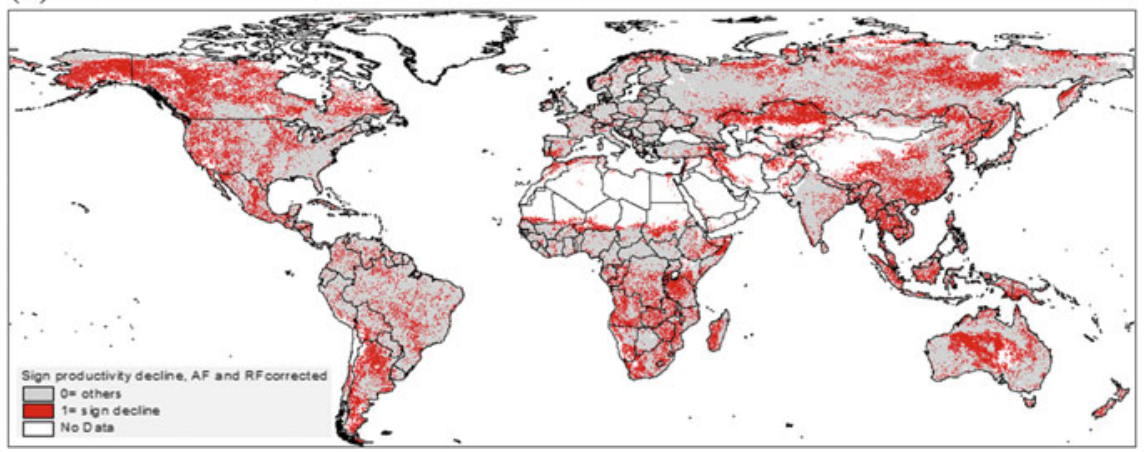

Fig. 4.9 Significant productivity decline with correction for both atmospheric and rainfall effects: a relative annual rate, b dummy scale (area in $r e d=40,540,352 \mathrm{~km}^{2}$ )

dense vegetation with Leaf Area Index (LAI) more than 4, the relationship between NDVI and the vegetation biomass tends to be saturated (i.e. NDVI is less sensitive to actual biomass change), thus should be used with special cautions (Carlson and Ripley 1997).

We calculated the mean annual LAI of the period 1982-2006 by using the GLASS LAI dataset (Liang and Xiao 2012; Xiao et al. 2014). To avoid the computational abundance (each year has 46 8-day LAI images), we calculated the mean of 8-day LAI in representative years 1985, 1990, 1995 and 2000 (i.e. $n=46 \times 4=184$ global images taken into account).

As a result, of 633,443 declined pixels in Fig. 4.9 there are 71,755 pixels (11\%) with LAI $>4$ possibly making their NDVI trend not reliable for indicating vegetation biomass productivity. Land degradation in these NDVI-saturated pixels should be considered with other indicators, rather than NDVI signals. Given the NDVI-saturated pixels masked, the area of biomass productivity decline is about 36 million $\mathrm{km}^{2}$, i.e. $24 \%$ of global land area. These areas are shown in Fig. 4.10a (in $\%$ of period-mean NDVIAF-adjusted) and Fig. 4.10b (in dummy scale). The map in Fig. 4.10a shows that most of NDVI degrading areas have small annual 
(a)

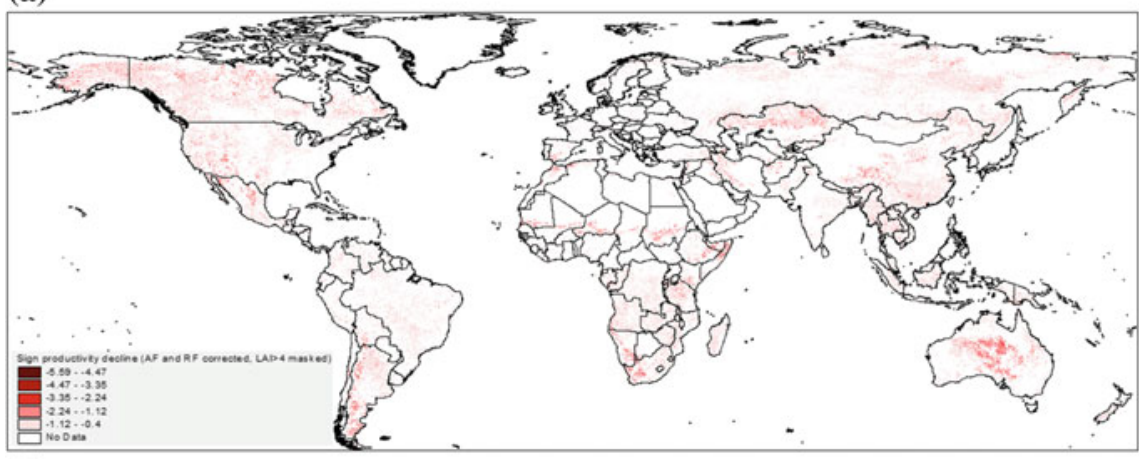

(b)

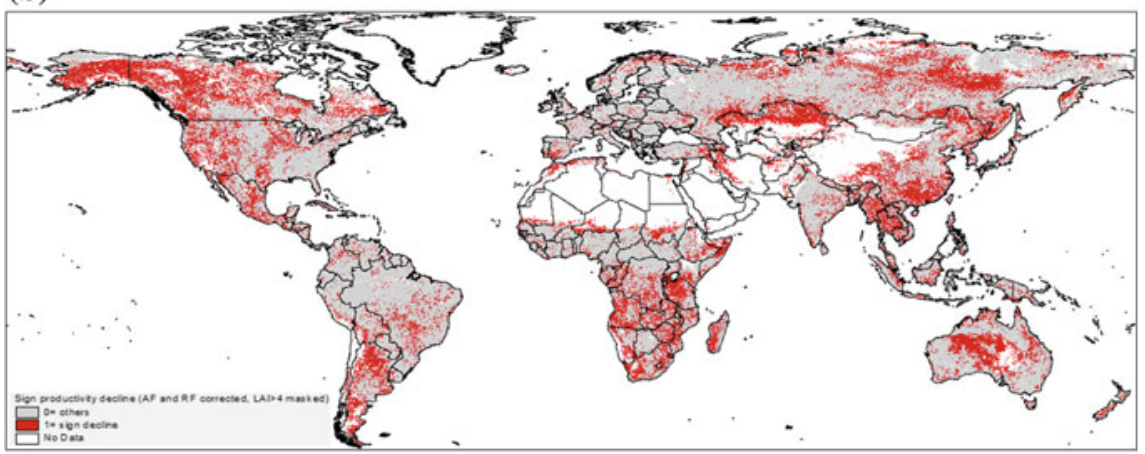

Fig. 4.10 Significant productivity decline with correction for rainfall and atmospheric fertilization effects and masking of NDVI-saturated pixels. a Relative annual rate, b dummy scale (area in red $=35,948,032 \mathrm{~km}^{2}$ )

reduction magnitude (i.e. less than $1 \% / y e a r$, as showed in the area in pink). Given the inherently high noise of NDVI signal, uncertainty of the calculated degrading trend in these pink areas can be higher than the pixels with higher annual NDVI reduction rate, i.e. the red to dark red pixels in Fig. 4.10a.

\section{Relation to Land Cover Strata}

At the resolution of this global study (i.e. 8-km pixel), many sub-classes of scattered land cover/use (e.g. slash-and-burn field, mountain paddy rice terraces and fruit plantations) will be dissimulated. Thus, we used 7 broad land use/cover classes (see Fig. 4.11) aggregated from 23 classes of the Globcover 2005-2006 data (Bicheron et al. 2008). The spatial pattern of long-term (1982-2006) NDVI decline with correction of RF and AF effects and masking of saturated NDVI zone versus main land cover/use types is shown in Fig. 4.11. The related statistics for regions in the 


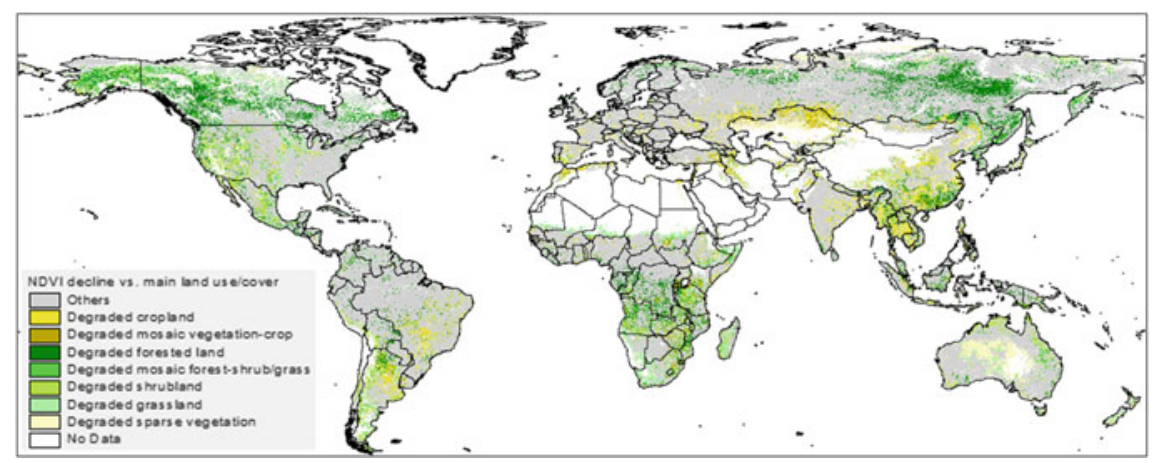

Fig. 4.11 Areas of long-term (1982-2006) NDVI decline (with correction of RF and AF effects and masking saturated NDVI zone) versus main land cover/use types

world are summarized by major world regions in Table 4.2 . Table 4.2 shows at varying magnitudes of land degradation according to land use/cover types and geographic regions. One of the key highlights of this summary is the substantial shares of degradation in grasslands and shrublands, especially in North Africa and Near East (52\%) and Sub-Saharan Africa (40\%), which negatively affects the livelihoods of especially the pastoralist communities. In a related note, about $43 \%$ of the areas with sparse vegetation are degraded in Asia. Quite often, these areas also serve as grazing grounds for ruminants, for example in Central Asia (Pender et al. 2009). The share of cropland degradation seems especially high in Asia (30 \%), North Africa and Near East (45\%), the regions with extensive irrigated agriculture.

These results in Fig. 4.11 and Table 4.2 should be treated with special cautions regarding the following aspects:

1. Although pixels of saturated greenness (LAI $>4$ ) are masked out, the indication of biomass production dynamics using inter-annual NDVI trend in the forested areas (data in 2005-2006) may not be reliable compared to those of herbaceous vegetation types. The reason would be that most biomass of closed forest is in the woody component whose annual dynamics (rather relatively slow or steady) may not be necessary well-related to annual greenness of the forest canopy (rather rapidly variable). Moreover, with forest ecosystems, especially those used for nature protection, biodiversity is often a prioritized task in the ecosystem assessments. However, increases of biomass production and/or soil nutrients may not necessarily be correlative with biodiversity maintenance. For example, invasion of exotic plant species can lead to high biomass productivity but dramatically reduce biodiversity, which is not desirable regarding the land-use purpose (Nkonya et al. 2013). Increasing of soil nutrients can reduce plant diversity in some cases (Chapin et al. 2000; Sala et al. 2000; Wassen et al. 2005). 


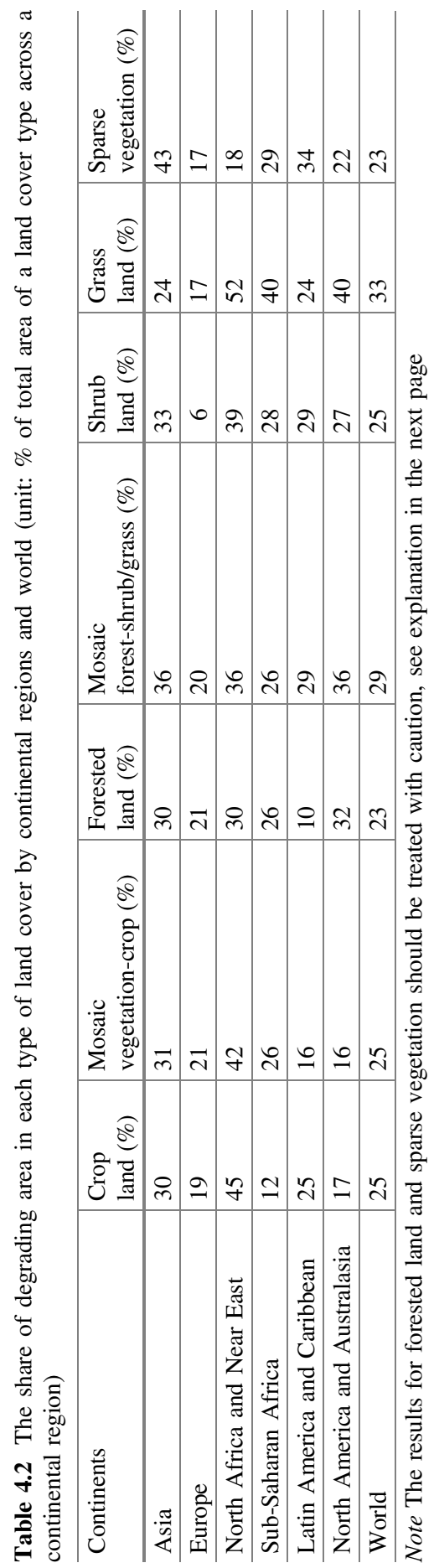


2. NDVI signal may not be a suitable indicator of degradation of sparse vegetation areas. When wet exposed soils tend to darken, i.e. soils' reflectance is a direct function of water content. If the spectral response to moistening is not exactly the same in the two spectral bands (IR and NIR), the NDVI of sparsely vegetative areas can appear to change as a result of soil moisture changes (precipitation or evaporation) rather than because of vegetation changes. ${ }^{1}$ Although soil-adjusted vegetation index (SAVIs) (Huete 1988) can help improve the correlation between the index and the actual vegetation status, vegetation biomass itself may be not so crucial for indicating the status of the exposed soil.

3. The attribution of "human-induced" degradation to the "rainfall- and atmospheric fertilization-corrected" NDVI decline makes sense in areas where there is no other natural drivers of biomass production decline besides the reduction of annual rainfall and atmospheric fertilization. Event-based wild fires which may be a factor that has likely reduced biomass production in remote, unpopulated regions like Alaska (Boles and Verbyla 2000) or the inland of the Australian continent (Kasischke and Penner 2004). Thus, the term "human-induced degradation" may be less applicable in these areas. Furthermore, the use of mean annual NDVI can reduce partly, but not eliminate completely the effects of change in the seasonality of weather parameters that are important in many climate change scenarios.

\section{Potential Soil Degradation Masked by Fertilizer Application}

The trend of above ground biomass productivity can be an indirect indicator of soil degradation or soil improvement if the nutrient source for vegetation/crop growth is solely, or largely, from the soils (i.e. soil-based biomass productivity). In the agricultural areas with intensive application of mineral fertilizers (i.e. fertilizerbased crop productivity), the net primary productivity principally cannot be a reliable indicator of soil fertility trend (Le 2012). In this case, alternative indicators of soil fertility should be used. Global patterns of fertilizer applications, based on data reported in around 2000 (Potter et al. 2010; MacDonald et al. 2011), are shown in Fig. 4.12. The amount of fertilizers used in East Asia (e.g. China and Vietnam), Northern India, Europe and in considerable areas in North America is equal to 18-20 times of those in sub-Saharan Africa (see Fig. 4.12 and Table 4.3), which has been only around $1 \mathrm{~kg} / \mathrm{ha} /$ year (Vlek et al. 1997). Although the global spatial data of fertilizer use is available for year 2000 or around, the estimated regional averages and trends (Table 4.4) show that the 2000 fertilizer use maps can be used to depict the relative global patterns of the study period. Pixels with remarkable fertilizer

\footnotetext{
${ }^{1}$ http://en.wikipedia.org/wiki/Normalized_Difference_Vegetation_Index.
} 
(a)

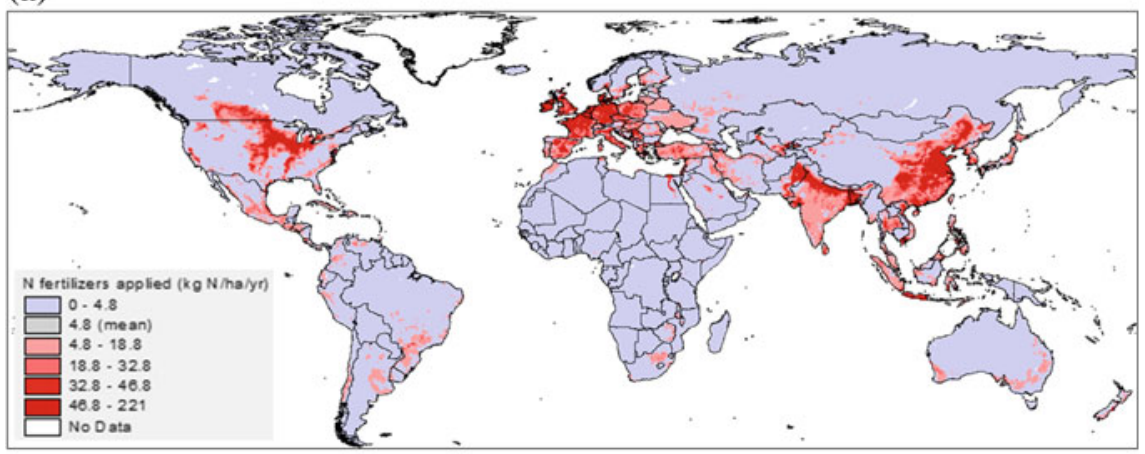

(b)

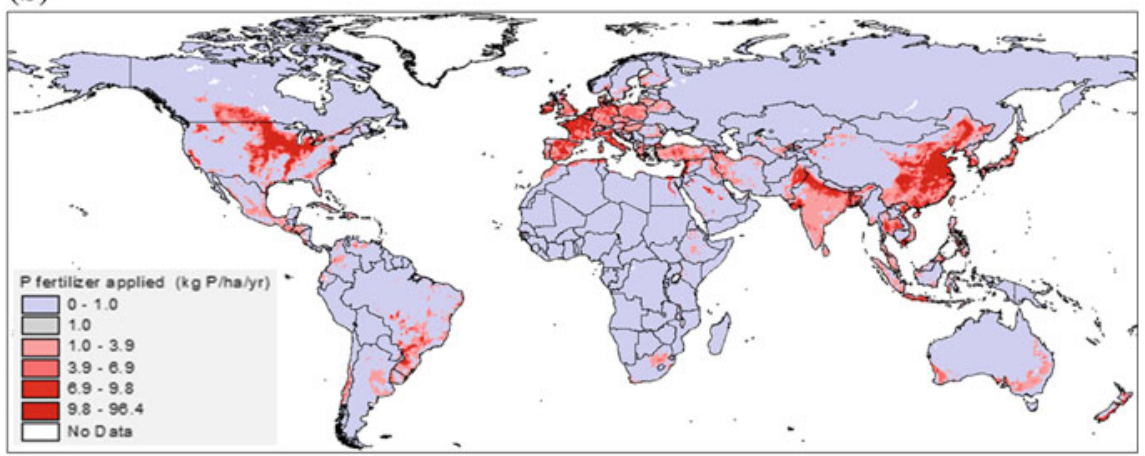

(c)

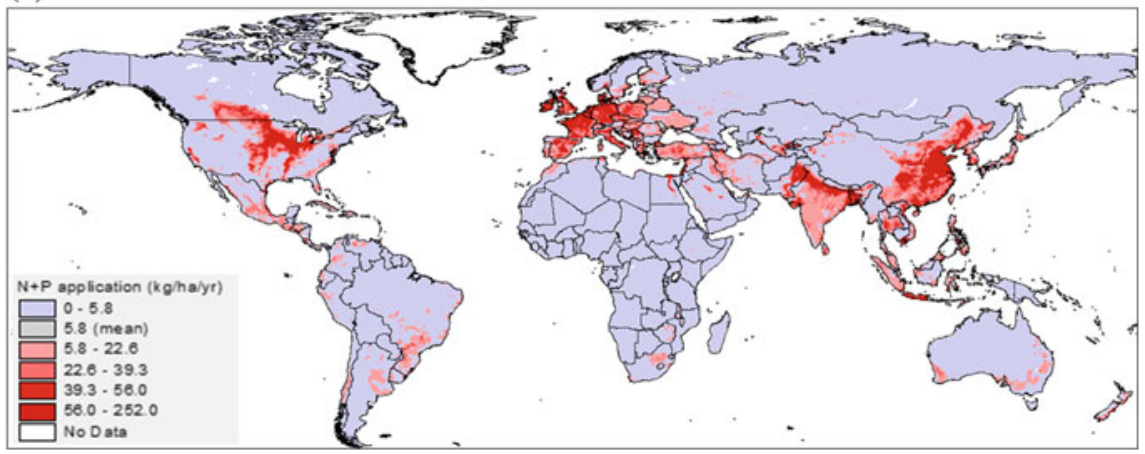

Fig. 4.12 Global patterns of $\mathrm{N}$ and $\mathrm{P}$ fertilizers application for major crops in 2000. Data sources Potter et al. (2010), MacDonald et al. (2011). a Application of nitrogen fertilizer, b application of phosphorus fertilizer, $\mathbf{c}$ combination of nitrogen and phosphorus application

application (e.g. $>5.8 \mathrm{~kg} / \mathrm{ha} / \mathrm{year}$, i.e. the global mean) and neutral biomass productivity trend, may have a potential risk of soil degradation that cannot be detected by NDVI-based analysis. These areas are shown in Fig. 4.13, accounting for about 7 million $\mathrm{km}^{2}$, or $4.8 \%$ of global land area. 
Table 4.3 Fertilizer consumptions in different regions of the world in 2011 (in million metric tons)

\begin{tabular}{l|l|l|l}
\hline Countries and regions & Nitrogen & Phosphorous & Potash \\
\hline China & 33.8 & 11.5 & 5.2 \\
\hline India & 17.4 & 8.0 & 2.6 \\
\hline United States & 12.1 & 4.0 & 4.3 \\
\hline East Asia & 41.7 & 14.1 & 9.5 \\
\hline South Asia & 22.0 & 9.2 & 3.0 \\
\hline North America & 14.4 & 4.8 & 4.6 \\
\hline Western and Central Europe & 10.3 & 2.4 & 2.7 \\
\hline Latin America and the Caribbean & 7.4 & 5.7 & 5.6 \\
\hline Eastern Europe and Central Asia & 4.4 & 1.2 & 1.3 \\
\hline West Asia & 2.9 & 1.1 & 0.3 \\
\hline Africa & 3.3 & 1.0 & 0.5 \\
\hline Sub-Saharan Africa & 1.7 & 0.6 & 0.4 \\
\hline World & 108 & 41 & 28 \\
\hline
\end{tabular}

Source International Fertilizer Association (www.ifa.org, accessed on 06 February 2014). The figures for Sub-Saharan Africa were calculated by the authors' based on country fertilizer consumption statistics for Africa given by IFA

Table 4.4 Fertilizer uses (in million tons) and average annual growth rates (in \%) in different periods

\begin{tabular}{l|l|l|l|l|l}
\hline \multirow{2}{*}{ Regions } & \multicolumn{3}{l|}{ Fertilizer use } & \multicolumn{2}{l}{ Annual growth } \\
\cline { 2 - 6 } & $1959 / 60$ & $1989 / 90$ & 2020 & $1960-90$ & $1990-2020$ \\
\hline East Asia & 1.2 & 31.4 & 55.7 & 10.9 & 1.9 \\
\hline South Asia & 0.4 & 14.8 & 33.8 & 12 & 2.8 \\
\hline West Asia and North Africa & 0.3 & 6.7 & 11.7 & 10.4 & 1.9 \\
\hline Latin America & 0.7 & 8.2 & 16.2 & 8.2 & 2.3 \\
\hline Sub-Saharan Africa & 0.1 & 1.2 & 4.2 & 5.5 & 1.2 \\
\hline World & 27.4 & 143.6 & 208 & 5.5 & 1.2
\end{tabular}

Data source FAO and the calculations by Bumb and Baanante (1996)

\section{Areas of Soil Improvement}

In addition to the areas with land degradation, we have also identified that there has been NDVI improvement in about $2.7 \%$ of global land area. The analysis identifies the areas of land improvement ("bright spots") by the increasing slope of inter-annual mean NDVIs: more by $10 \%$ or more over 25 years and at $90 \%$ statistical significance. This is also adjusted/corrected for rainfall and atmospheric fertilization effects, LAI < 4), (Fig. 4.14).

The major "bright spots" of land improvement are located in the Sahelian belt in Africa, Central parts of India, western and eastern coasts of Australia, central Turkey, areas of North-Eastern Siberia in Russia, and north-western parts of Alaska in the US. 


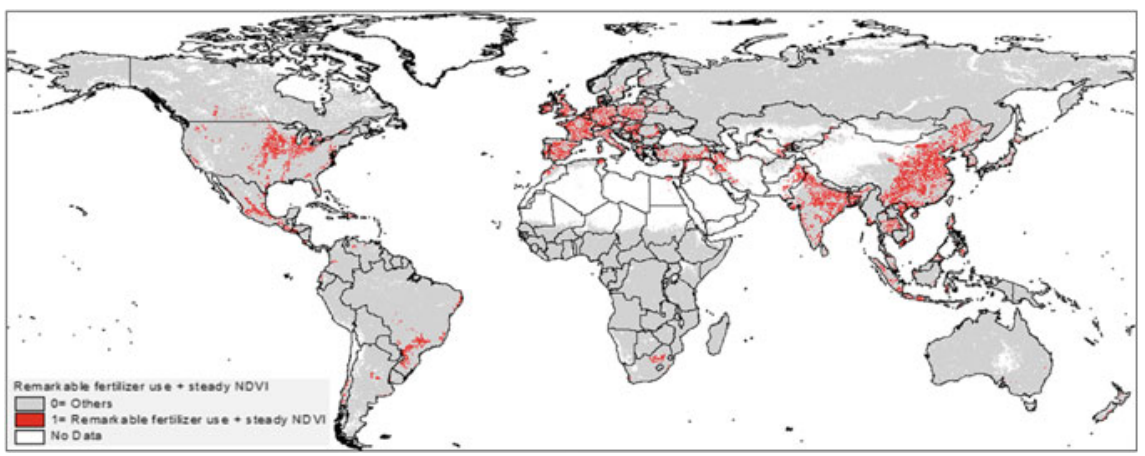

Fig. 4.13 Pixels with remarkable fertilizer application (e.g. $\geq 12 \mathrm{~kg} \mathrm{~N}+\mathrm{P} / \mathrm{ha} / \mathrm{year}=$ twice of the global mean) but with neutral trend of biomass productivity, may have a potential risk of soil degradation

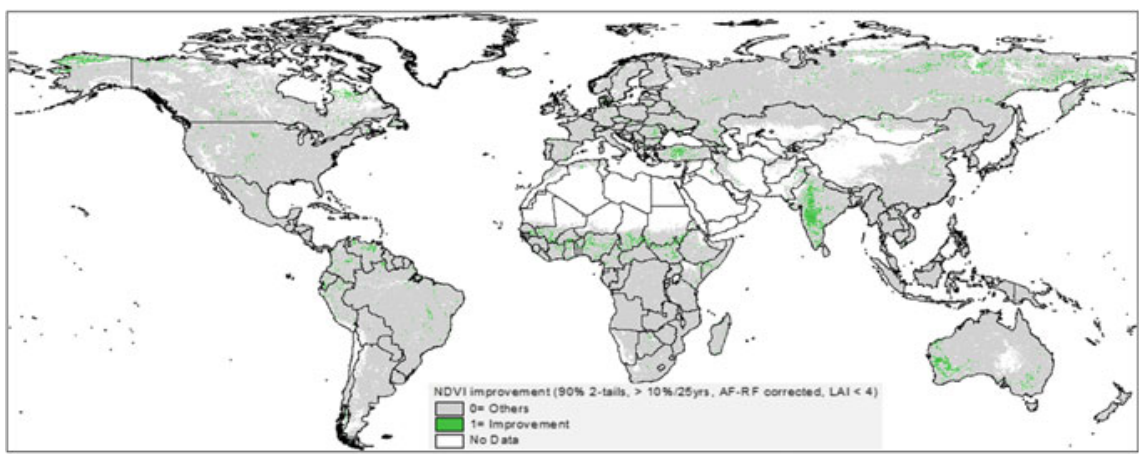

Fig. 4.14 The areas of NDVI improvement, with slope of inter-annual mean NDVIs $\geq 10 \%$ over 25 year and $90 \%$ statistically significant, adjusted/corrected for RF and AF effects, LAI $<4$

Overlaying land degradation (Figs. 4.10 and 4.13) with population density projections for 2010 (CIESIN-CIAT 2005) shows that about 3.2 billion people are currently residing in degrading areas. Of this total number, about 0.6 billion people live in areas where land degradation is directly observed in the remotely sensed data, another 1.2 billion people live in areas where land degradation is likely masked by rainfall dynamics and atmospheric fertilization effects, finally, another 1.3 billion people reside in areas where chemical fertilization may be masking soil and land degradation. The regional breakdown of the population residing in degrading areas is given in Table 4.5. The biggest number of people residing in degrading areas is found in Asia, followed Europe, Middle East and North Africa, Latin America and Caribbean, Sub-Saharan Africa and finally, North America and Australasia. In terms of the share of people residing in degrading areas, the most 


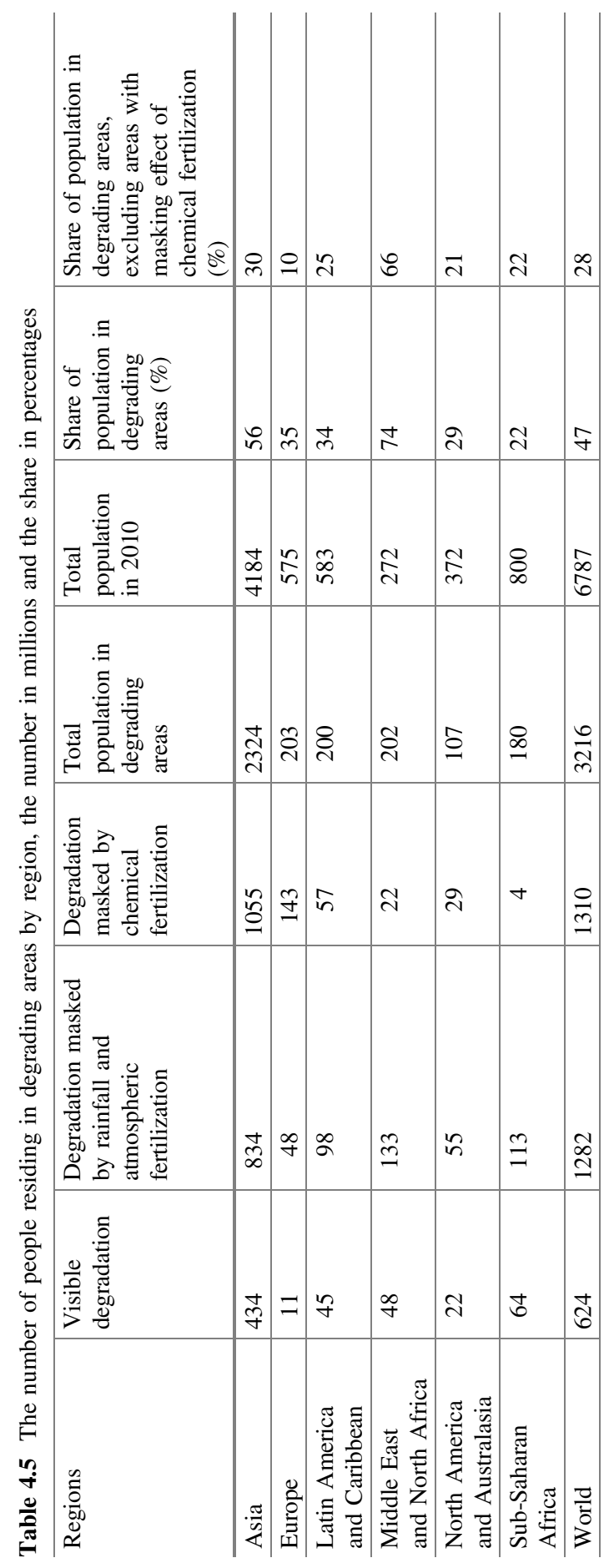


affected are Middle East and North Africa, and Asia. In Asia and Europe, the higher shares of land degradation and of people residing in degrading areas are found in areas where land degradation might be masked by chemical fertilizer application. Whereas in other regions, visible decline and masking effects of rainfall and atmospheric fertilization seem to dominate. One caveat, these are still somewhat conservative estimates of the livelihoods which have potentially been affected by land degradation, because the number of people affected by land degradation is likely to be higher due to off-site and indirect externalities of land degradation.

\section{Conclusions}

In this study, we advance our knowledge by making the following relatively new contributions. Firstly, the major contribution of this global study is the identification of regions where degradation magnitude and extent are relatively high for prioritizing both preventive investments for the restoration or reclamation of degraded land, and subsequent focal ground-based studies. The map of degradation hotspots is different from the production of an accurate map of all degraded areas that seems impractical at global level due to lacking data on many aspects of land degradation. Secondly, we account for masking effects of rainfall dynamics, atmospheric and anthropogenic fertilizations. To our knowledge, there has been no previous published study at global level accounting for all these masking factors. Moreover, we also identify the areas where land improvement has occurred.

The results show that land degradation hotspots stretch to about $29 \%$ of the total global land area and are occurring across all agro-ecologies. One third of this degradation is directly identifiable from a statistically significant declining trend in NDVI. However, the remaining two thirds of this degradation are concealed by rainfall dynamics, atmospheric fertilization and application of chemical fertilizers. Globally, human-induced biomass productivity decline are found in $25 \%$ of croplands and vegetation-crop mosaics, $29 \%$ of mosaics of forests with shrub- and grasslands, $25 \%$ of shrublands, and $33 \%$ of grasslands, as well as $23 \%$ of areas with sparse vegetation. The share of degrading croplands is likely to increase further when we take into account the croplands where intensive fertilizer application may be masking land degradation. Although this study does find land degradation to be a massive problem in croplands, it also emphasizes, in contrast to most previous similar studies, the extent of degradation in areas used for livestock grazing by pastoral communities, including grasslands, shrublands, their mosaics, and areas with sparse vegetation. In most countries, livestock production and its value chains produce comparable economic product and incomes for rural populations as crop production. In total, there are about 3.2 billion people who reside in these degrading areas. However, the true number of people affected by land degradation is likely to be higher, because even those people residing outside these degrading areas may be dependent on the continued flow of ecosystem goods and services from the degrading areas. 
It is quite encouraging that about $2.7 \%$ of the global land mass has experienced significant improvement of biomass productivity over the last 25 years. However, the improving figure is modest as being 10 times smaller than the extent of areas with degrading lands, resulting extremely high net land degradation over the globe. Achieving the goal of Zero Net Land Degradation (Lal et al. 2012) would, therefore, require considerable multiplication of efforts to rehabilitate degraded lands and also prevent further increasing rates of land degradation.

Despite being an advancement to the past studies on global land degradation mapping, the current work has several limitations. First, conceptually and practically the present study capture only the "primary productivity" aspect of land degradation. The other important aspects of land degradation such as soil/water pollution and biodiversity, which do not necessarily correlate with primary productivity, are still out of the scope of this study. Secondly, some degraded areas may not be captured by the NDVI-based assessment employed here, such as: the areas facing both human-induced and climate-driven declines, and areas facing biodiversity decline in natural vegetation. Thirdly, robustness of some key parametric procedures needs to be further evaluated. Moreover, the delineated degradation hotspots need to be validated by ground-level studies. This ground-level verification work is planned as the next step of our research activities. Further research is also required for evaluating the robustness and uncertainties of the presented results. The reported results (Figs. 4.11, 4.13 and Table 4.2) should be used as rough guides for geographic focus/prioritization in regional/national studies. The first activity of follow-up regional/national studies is to conduct activities for validating the "potential" hotspots. These may include the use of independent data, e.g. finer NDVI time-series like MODIS, accurate land cover change over the study period, soil degradation assessment (modeled erosion, leaching, change in key soil properties) (e.g. Le et al. 2012), change in species composition (e.g. Mbow et al. 2013), fertilizer/water uses and yields.

The drivers of land degradation are numerous, complex and interrelated (Nkonya et al. 2011; Pender et al. 2009; Chap. 7). In most cases, the effects of different land degradation drivers are modulated by context-specific factors (Nkonya et al. 2013), necessitating local level in depth studies to identify the role of various factors on land degradation and improvement. The results of global level correlative studies comparing several factors, such as population pressure, income per capita, poverty rates, governance (Vlek et al. 2010; Nkonya et al. 2011; Vu et al. 2014a, b) with land degradation provide with broadly useful estimates, but remain equivocal, due to difficulty of appropriately accounting for various omitted variables and endogeneity issues at such a broad scale. The results of this study are planned to be validated at the local level, and also would serve as a basis for the in-depth analysis of land degradation drivers through country case studies.

Open Access This chapter is distributed under the terms of the Creative Commons Attribution Noncommercial License, which permits any noncommercial use, distribution, and reproduction in any medium, provided the original author(s) and source are credited. 


\section{References}

Bai, Z., Dent, D., Yu, Y., \& de Jong, R. (2013). Land degradation and ecosystem services. In R. Lal, L. Lorenz, R. F. Hüttle, B. U. Schneider, \& J. Von Braun (Eds.), Ecosystem services and carbon sequestration in the biosphere (pp. 357-381). Dordrecht: Springer.

Bai, Z. G., Dent, D. L., Olsson, L., \& Schaepman, M. E. (2008a). Global assessment of land degradation and improvement 1. Identification by remote sensing. Report 2008/01. Wageningen: ISRIC-World Soil Information.

Bai, Z. G., Dent, D. L., Olsson, L., \& Schaepman, M. E. (2008b). Proxy global assessment of land degradation. Soil Use and Management, 24, 223-234.

Bicheron, P., Defourny, P., Brockmann, C., Schouten, L., Vancutsem, C., Huc, M., et al. (2008). GLOBCOVER: Products Description and Validation Report. http://due.esrin.esa.int/globcover/ LandCover_V2.2/GLOBCOVER_Products_Description_Validation_Report_I2.1.pdf. ESA Globcover Project, led by MEDIAS-France/POSTEL.

Boisvenue, C., \& Running, S. W. (2006). Impacts of climate change on natural forest productivity -Evidence since the middle of the 20th century. Global Change Biology, 12, 862-882.

Boles, S. H., \& Verbyla, D. B. (2000). Comparison of three AVHRR-based fire detection algorithms for interior Alaska. Remote Sensing of Environment, 72, 1-16.

Brown, M. E., Pinzon, J. E., Didan, K., Morisette, J. T., \& Tucker, C. J. (2006). Evaluation of the consistency of long-term NDVI time series derived from AVHRR, SPOT-Vegetation, SeaWIFS, MODIS and LandSAT ETM+. IEEE Transactions Geoscience and Remote Sensing, 44, 1787-1793.

Buitenwerf, R., Bond, W. J., Stevens, N., \& Trollope, W. S. W. (2012). Increased tree densities in South African savannas: $>50$ years of data suggests $\mathrm{CO}_{2}$ as a driver. Global Change Biology, $18,675-684$.

Bumb, B. L., \& Baanante, C. A. (1996). World trends in fertilizers use and projections to 2020. In 2020 BRIEF-A 2020 Vision for Food, Agriculture, and the Environment 38 (October 1996), $1-2$.

Carlson, T. N., \& Ripley, D. A. (1997). On the relation between NDVI, fractional vegetation cover, and leaf area index. Remote Sensing of Environment, 62, 241-252.

Center for International Earth Science Information Network (CIESIN), Centro Internacional de Agricultura Tropical (CIAT). 2005. Gridded Population of the World Version 3 (GPWv3): Population Density Grids. http://sedac.ciesin.columbia.edu/gpw (Accessed on May 012013 ). Socio-economic Data and Applications Center (SEDAC), Columbia University, Palisades, NY.

Chapin, F. S. I., Zavaleta, E. S., Eviner, V. T., Naylor, R. L., Vitousek, P. M., Reynolds, H. L., et al. (2000). Consequences of changing biodiversity. Nature, 405, 234-242.

Conijn, J. G., Bai, Z. G., Bindraban, P. S., \& Rutgers, B. (2013). Global changes of net primary productivity, affected by climate and abrupt land use changes since 1981-Towards mapping global soil degradation. Report 2013/01. Wageningen: ISRIC-World Soil Information.

de Jong, R., de Bruin, S., de Wit, A., Schaepman, M. E., \& Dent, D. L. (2011). Analysis of monotonic greening and browning trends from global NDVI time-series. Remote Sensing of Environment, 115, 692-702.

de Jong, R., Verbesselt, J., Schaepman, M. E., \& de Bruin, S. (2012). Trend changes in global greening and browning: Contribution of short-term trends to longer-term change. Global Change Biology, 18, 642-655.

Dent, D., Bai, Z., Schaepman, M. E., \& Olsson, L. (2009). Letter to the editor-Response to wessels: Comments on 'Proxy global assessment of land degradation'. Soil Use and Management, 25, 93-97.

Dentener, F. J. (2006). Global maps of atmospheric nitrogen deposition, 1860, 1993 and 2050Data set. Oak Ridge National Laboratory, Distributed Active Archive Center, Oak Ridge, Tennessee, USA.

Diamond, J. (2005). Collapse: How societies choose to fail or succeed. New York, NY: Viking. 
Dregne, H. E. (1977). Generalized map of the status of desertification of arid lands. Report presented in the 1977 United Nations conference on desertification. FAO, UNESCO and WMO.

Dubovyk, O., Menz, G., Conrad, C., Kan, E., Machwitz, M., \& Khamzina, A. (2013). Spatio-temporal analyses of cropland degradation in the irrigated lowlands of Uzbekistan using remote-sensing and logistic regression modeling. Environmental Monitoring and Assessment, $185,4775-4790$.

Eswaran, H., Lal, R., \& Reich, P. (2001). Land degradation: An overview. In E. Bridges, I. Hannam, L. Oldeman, F. Penning de Vries, S. Scherr, S. Sompatpanit (Eds.), In Responses to Land Degradation. Proceedings of 2nd International Conference on Land Degradation and Desertification in Khon Kaen, Thailand. New Delhi: Oxford Press.

Evans, J., \& Geerken, R. (2004). Discrimination between climate and human-induced dryland degradation. Journal of Arid Environments, 57, 535-554.

Fensholt, R., Langanke, T., Rasmussen, K., Reenberg, A., Prince, S. D., Tucker, C., et al. (2012). Greenness in semi-arid areas across the globe 1981-2007 — an Earth Observing Satellite based analysis of trends and drivers. Remote Sensing of Environment, 121, 144-158.

Fensholt, R., Rasmussen, K., Kaspersen, P., Huber, S., Horion, S., \& Swinnen, E. (2013). Assessing Land Degradation/Recovery in the African Sahel from Long-Term Earth Observation Based Primary Productivity and Precipitation Relationships. Remote Sensing, 5, 664-686.

Fensholt, R., Rasmussen, K., Nielsen, T. T., \& Mbow, C. (2009). Evaluation of earth observation based long term vegetation trends: Intercomparing NDVI time series trend analysis consistency of Sahel from AVHRR GIMMS, Terra MODIS and SPOT VGT data. Remote Sensing of Environment, 113, 1886-1898.

GLCF, accessed in 01 May (2013). Global Inventory Modeling and Mapping Studies (GIMMS) AVHRR $8 \mathrm{~km}$ Normalized Difference Vegetation Index (NDVI), Bimonthly 1981-2006. Product Guide. http://glcf.umd.edu/library/guide/GIMMSdocumentation_NDVIg_GLCF.pdf. Global Land Cover Facility (GLCF), the University of Maryland.

Hellden, U., \& Tottrup, C. (2008). Regional desertification: A global synthesis. Global and Planetary Change, 64, 169-176.

Herrmann, S., Assaf, A., \& Compton, J. T. (2005). Recent trends in vegetation dynamics in the African Sahel and their relationship to climate. Global Environmental Change, 15, 394-404.

Hill, J., Stellmes, M., Udelhoven, T., Roder, A., \& Sommer, S. (2008). Mediterranean desertification and land degradation: Mapping related land use change syndromes based on satellite observations. Global and Planetary Change, 64, 146-157.

Huete, A. R. (1988). A soil-adjusted vegetation index (SAVI). Remote Sensing of Environment, 25, 295-309.

Jones, P., \& Harris, I. (2008). CRU Time-Series (TS) High Resolution Gridded Datasets. http:// badc.nerc.ac.uk/view/badc.nerc.ac.uk_ATOM_dataent_1256223773328276 (Accessed on May 01 2013). NCAS British Atmospheric Data Centre Climate Research Unit (CRU), University of East Anglia.

Kasischke, E. S., \& Penner, J. E. (2004). Improving global estimates of atmospheric emissions from biomass burning. Journal of Geophysical Research, 109(D14S01).

Lal, R., Safriel, U., \& Boer, B. (2012). Zero net land degradation: A new sustainable development goal for Rio+ 20. Secretariat of the United Nations Convention to Combat Desertification (UNCCD), pp. 1-30. URL http://www.unccd.int/Lists/SiteDocumentLibrary/secretariat/2012/ Zero\%2020Net\%2020Land\%2020Degradation\%2020Report\%2020UNCCD\%2020May\% 202012\%202020background.pdf (Accessed 202020 August 202013).

Le, Q. B. (2012). Indicators of global soils and land degradation. Slides of Oral Presentation at the First Flobal Soil Week, November 18-22 2012, Berlin, Germany. The First Global Soil Week, Berlin.

Le, Q. B., Tamene, L., \& Vlek, P. L. G. (2012). Multi-pronged assessment of land degradation in West Africa to assess the importance of atmospheric fertilization in masking the processes involved. Global and Planetary Change, 92-93, 71-81. 
Lewis, S. L., Lopez-Gonzalez, G., Sonké, B., Affum-Baffoe, K., \& Baker, T. R. (2009). Increasing carbon storage in intact African tropical forests. Nature, 457, 1003-1006.

Liang, S., \& Xiao, Z. (2012). Global land surface products: Leaf area index product data collection (1985-2010). Beijing: Beijing Normal University.

MacDonald, G. K., Bennett, E. M., Potter, P. A., \& Ramankutty, N. (2011). Agronomic phosphorus imbalances across the world's croplands. Proceedings of the National Academy of Sciences of the United States of America, 108, 3086-3091.

Markon, C. J., Fleming, M. D., \& Binnian, E. F. (1995). Characteristics of vegetation phenology over the Alaskan landscape using AVHRR time-series data. Polar Record, 31, 179-190.

Mbow, C., Fensholt, R., Rasmussen, K., \& Diop, D. (2013). Can vegetation productivity be derived from greenness in a semi-arid environment? Evidence from ground-based measurements. Journal of Arid Environments, 97, 56-65.

MEA. (2005). Ecosystems and Human Well-being: Synthesis. Washington DC: Millennium Ecosystem Assessment.

Nachtergaele, F., \& Petri, M. (2008). Mapping land use systems at global and regional scales for land degradation assessment analysis. Rome: FAO.

Nkonya, E., Braun, Jv, A, Mirzabaev, Le, Q. B., Kwon, H. Y., \& Kirui, O. (2013). Economics of Land Degradation Initiative: Methods and Approach for Global and National Assessments. ZEF-Discussion Papers on Development Policy, 183, 1-41.

Nkonya, E., Gerber, N., Baumgartner, P., von Braun, J., De Pinto, A., \& Graw, V., et al. (2011). The economics of desertification, land degradation, and drought-Toward an integrated global assessment. ZEF-Discussion Papers on Development Policy No. 150, Center for Development Research (ZEF).

Oldeman, L. R., Hakkeling, R. T. A., \& Sombroek, W. G. (1990). World map of the status of human-induced soil degradation: An explanatory note ( $2 \mathrm{nd}$ ed.). Wageningen, The Netherlands: International Soil Reference and Information Centre.

Pender, J., Mirzabaev, A., \& Kato, E. (2009). Economic Analysis of Sustainable Land Management Options in Central Asia. Final Report for the ADB. IFPRI/ICARDA, 168.

Pettorelli, N., Vik, J. O., Mysterud, A., Gaillard, J.-M., Tucker, C. J., \& Stenseth, N. C. (2005). Using the satellite-derived NDVI to assess ecological responses to environmental change. Trends in Ecology \& Evolution, 20, 503-510.

Pinter, P. J., Jackson, R. D., Elaine Ezra, C., \& Gausman, H. W. (1985). Sun-angle and canopy-architecture effects on the spectral reflectance of six wheat cultivars. International Journal of Remote Sensing, 6, 1813-1825.

Pinzon, J., Brown, M. E., \& Tucker, C. J. (2005). Satellite time series correction of orbital drift artifacts using empirical mode decomposition. In N. E. Huang \& S. S. P. Shen (Eds.), Hilbert-Huang transform and its applications (pp. 167-186). Singapore: World Scientific Publishing.

Potter, P., Ramankutty, N., Bennett, E. M., \& Donner, S. D. (2010). Characterizing the spatial patterns of global fertilizer application and manure production. Earth Interactions 14. Paper No. 2, 22 p. doi:210.1175/2009ei1288.1171.

Reay, D. S., Dentener, F., Smith, P., Grace, J., \& Feely, R. (2008). Global nitrogen deposition and carbon sinks. Nature Geoscience, 1, 430-437.

Safriel, U. N. (2007). The assessment of global trends in land degradation. In M. V. K. Sivakumar, \& Ndiang'ui, N. (Eds.), Climate and land degradation (pp. 1-38). Berlin: Springer.

Sala, O. E., Chapin, F. S. I., Armesto, J. J., Berlow, E., Bloomfield, J., Dirzo, R., et al. (2000). Global biodiversity scenarios for the year 2100. Science, 287, 1770-1774.

Sommer, S., Zucca, C., Grainger, A., Cherlet, M., Zougmore, R., Sokona, Y., et al. (2011). Application of indicator systems for monitoring and assessment of desertification from national to global scales. Land Degradation and Development, 22, 184-197.

Thomas, W. (1997). A three-dimensional model for calculating reflection functions of inhomogeneous and orographically structured natural landscapes. Remote Sensing of Environment, 59, 44-63. 
Trabucco, A., \& Zomer, R. J. (2009). Global Aridity Index (Global-Aridity) and Global Potential Evapo-Transpiration (Global-PET) Geospatial Database. CGIAR Consortium for Spatial Information, CGIAR-CSI GeoPortal: http://www.csi.cgiar.org.

Tucker, C. J., Pinzon, J. E., Brown, M. E., Slayback, D. A., Pak, E. W., Mahoney, R., et al. (2005). An extended AVHRR 8-km NDVI data set compatible with MODIS and SPOT Vegetation NDVI data. International Journal of Remote Sensing, 26, 4485-4498.

UNCCD. (2004). UNCCD Ten Years On. Secretariat of the United Nations Convention to Combat Desertification (UNCCD), Bonn, Germany.

USDA-NRCS. (1998). Global Desertification Vulnerability Map. U.S. Department of Agriculture, Natural Resources Conservation Science (USDA-NRCS). http://www.nrcs.usda.gov/wps/ portal/nrcs/detail/national/nedc/training/soil/?cid=nrcs142p2_054003 (Accessed on May 31 2014).

Vlek, P., Le, Q. B., \& Tamene, L. (2010). Assessment of land degradation, its possible causes and threat to food security in Sub-Saharan Africa. In R. Lal \& B. A. Stewart (Eds.), Food security and soil quality (pp. 57-86). Boca Raton, Florida: CRC Press.

Vlek, P. L. G., Kühne, R. F., \& Denich, M. (1997). Nutrient resources for crop production in the tropics. Philosophical Transactions of the Royal Society of London. Series B, Biological sciences, 352, 975-985.

Vlek, P. L. G., Le, Q. B., \& Tamene, L. (2008). Land decline in land-rich Africa: A creeping disaster in the making. Rome, Italy: CGIAR Science Council Secretariat.

Vogt, J. V., Safriel, U., Maltitz, G. V., Sokona, Y., Zougmore, R., Bastin, G., \& Hill, J. (2011). Monitoring and assessment of land degradation and desertification: Towards new conceptual and integrated approaches. Land Degradation and Development, 22, 150-165.

Vu, Q. M., Le, Q. B., \& Vlek, P. L. G. (2014a). Hotspots of human-induced biomass productivity decline and their social-ecological types towards support national policy and local studies on land degradation. Global and Planetary Change, 121, 64-77.

Vu, Q. M., Le, Q. B., Frossard, E., \& Vlek, P. L. G. (2014b). Socio-economic and biophysical determinants of land degradation in Vietnam: An integrated causal analysis at the national level. Land Use Policy, 36, 605-617.

Wassen, M. J., Olde Venterink, H., Lapshina, E. D., \& Tanneberger, F. (2005). Endangered plants persist under phosphorus limitation. Nature, 437, 547-550.

Wessels, K. J., Prince, S. D., Malherbe, J., Small, J., Frost, P. E., \& VanZyl, D. (2007). Can human-induced land degradation be distinguished from the effects of rainfall variability? A case study in South Africa. Journal of Arid Environments, 68, 271-297.

Xiao, Z., Liang, S., Wang, J., Chen, P., Yin, X., Zhang, L., \& Song, J. (2014). Use of general regression neural networks for generating the GLASS leaf area index product from time-series MODIS surface reflectance. IEEE Transactions on Geoscience and Remote Sensing, 52, 209-223. 